\title{
Modular HTGR Safety Basis and Approach
}

August 2011

The INL is a

U.S. Department of Energy National Laboratory

operated by

Battelle Energy Alliance

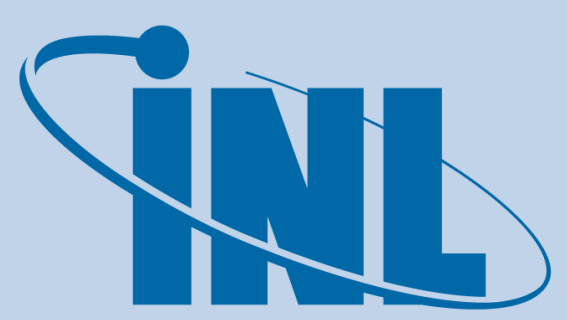

Idaho National Laboratory 


\section{DISCLAIMER}

This information was prepared as an account of work sponsored by an agency of the U.S. Government. Neither the U.S. Government nor any agency thereof, nor any of their employees, makes any warranty, expressed or implied, or assumes any legal liability or responsibility for the accuracy, completeness, or usefulness, of any information, apparatus, product, or process disclosed, or represents that its use would not infringe privately owned rights. References herein to any specific commercial product, process, or service by trade name, trade mark, manufacturer, or otherwise, does not necessarily constitute or imply its endorsement, recommendation, or favoring by the U.S. Government or any agency thereof. The views and opinions of authors expressed herein do not necessarily state or reflect those of the U.S. Government or any agency thereof. 


\title{
Modular HTGR Safety Basis and approach
}

August 2011

\author{
Idaho National Laboratory \\ Next Generation Nuclear Plant Project \\ Idaho Falls, Idaho 83415
}

http://www.inl.gov

Prepared for the

U.S. Department of Energy

Office of Nuclear Energy

Under DOE Idaho Operations Office

Contract DE-AC07-05ID14517 

Next Generation Nuclear Plant Project

Modular HTGR Safety Basis and Approach

INLEXT-11-22708

August 2011

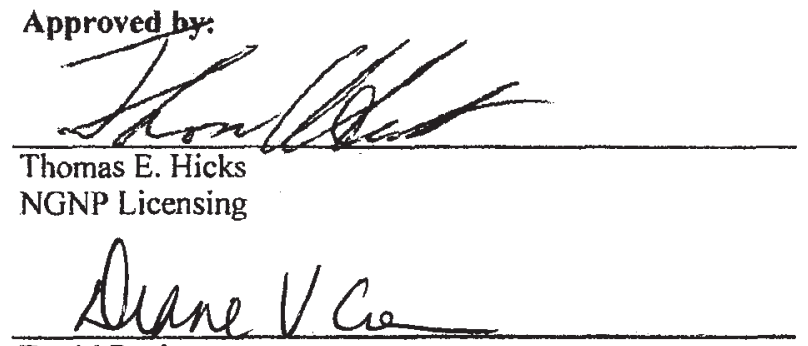

David Patti VHTR TDO Director
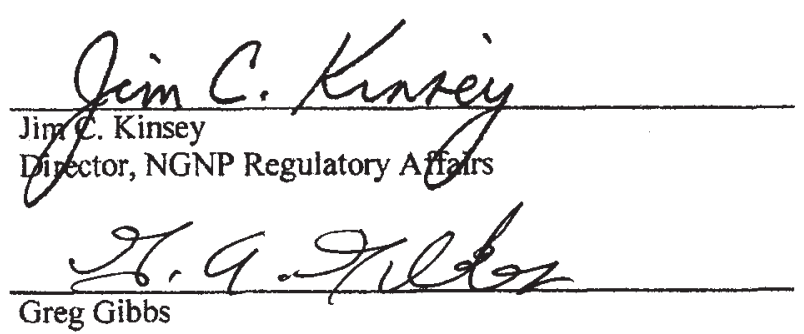

Director, NGNP Project
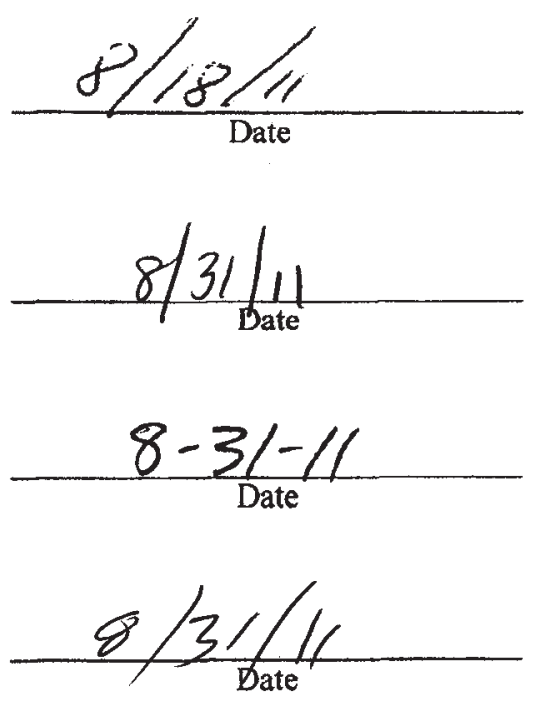



\begin{abstract}
The Next Generation Nuclear Plant (NGNP) will be a licensed commercial high temperature gas-cooled reactor (HTGR) capable of producing electricity and/or high temperature process heat for industrial markets supporting a range of end-user applications. Nuclear Regulatory Commission (NRC) licensing of the NGNP plant will demonstrate the efficacy of licensing future HTGRs for commercial industrial applications. This information paper supports other white papers submitted to address key generic issues of the priority licensing topics as part of the process for establishing HTGR regulatory requirements.

This information paper provides a summary level introduction to HTGR history, public safety objectives, inherent and passive safety features, radionuclide release barriers, functional safety approach, and risk-informed safety approach.

The information in this paper is intended to further the NRC staff and public stakeholders understanding of the modular HTGR safety approach. The NGNP project is not requesting any NRC action or specific feedback on this information paper because other white papers are addressing key generic issues associated with priority licensing topics in greater detail.
\end{abstract}




\section{CONTENTS}

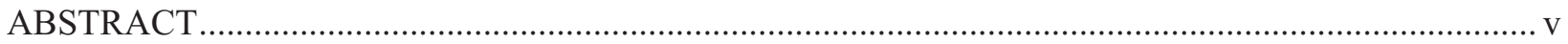

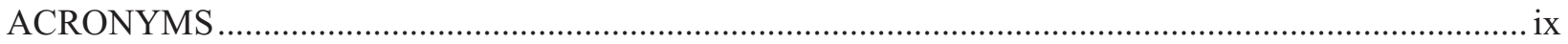

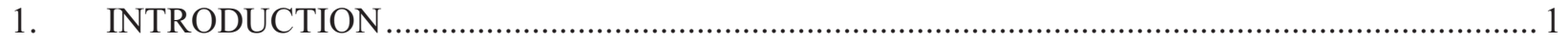

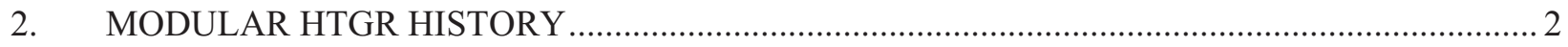

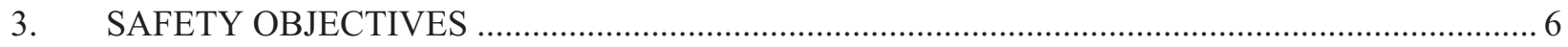

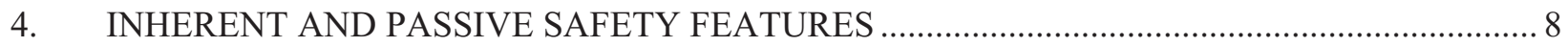

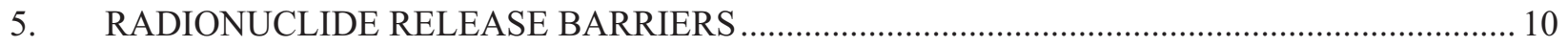

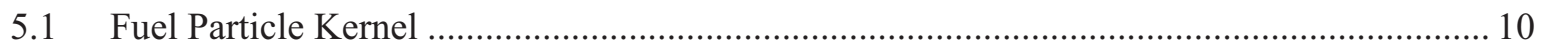

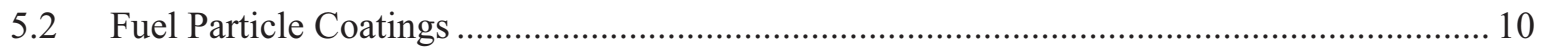

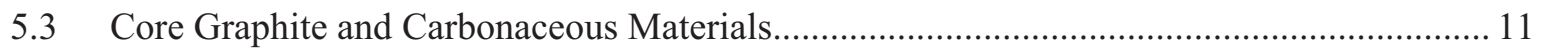

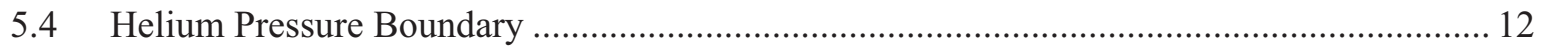

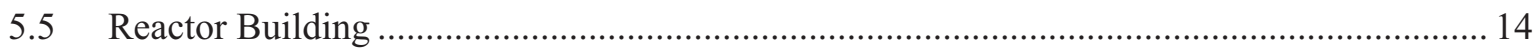

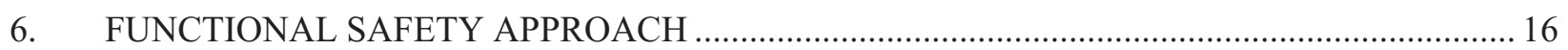

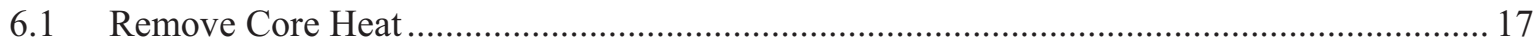

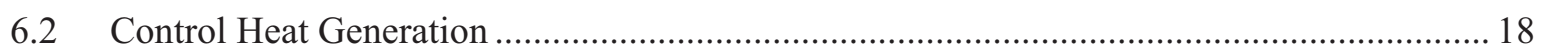

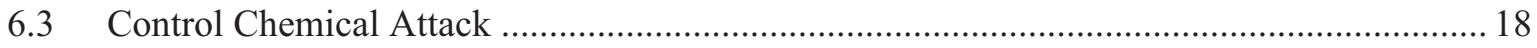

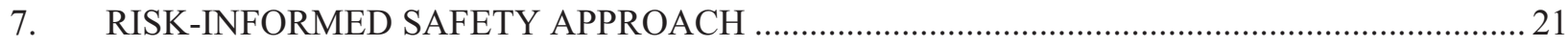

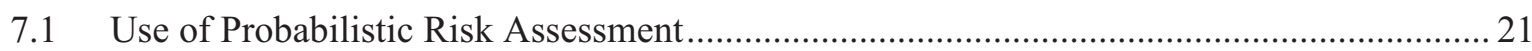

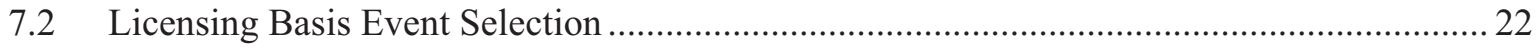

7.3 Structures, Systems, and Components Safety Classification .............................................. 23

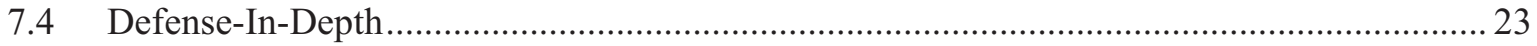

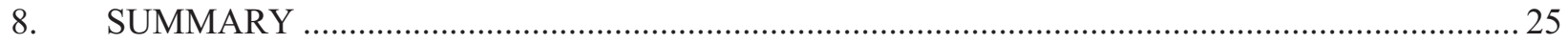

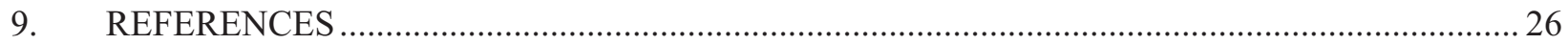

Appendix A-History of the International Development of High Temperature Gas-Cooled

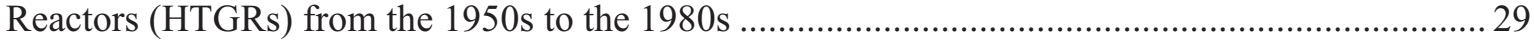

\section{FIGURES}

Figure 1. SC-MHR demonstration plant general arrangement. ............................................................. 4

Figure 2. SC-MHR demonstration plant configuration....................................................................... 5

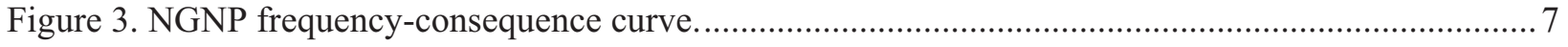

Figure 4. TRISO-Coated Fuel Particle Cross Section......................................................................... 8

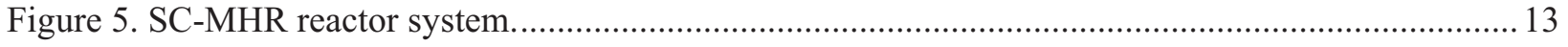


Figure 6. Pebble bed HTR-module primary circuit.

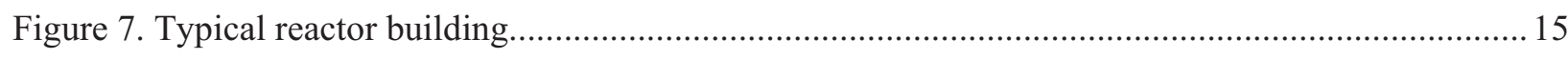

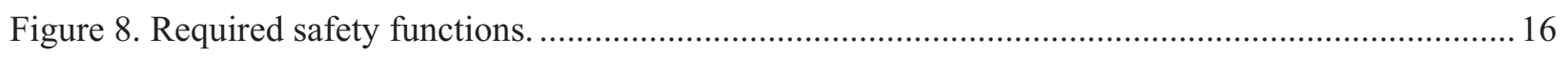

Figure 9. Relationship between NGNP safety basis white papers..................................................... 17

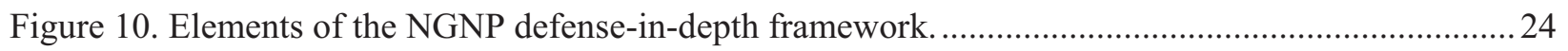




\section{ACRONYMS}

AC Alternating Current

AOO Anticipated Operational Occurrence

ASME American Society of Mechanical Engineers

AVR Arbeitsgemeinschaft Versuchsreaktor

BDBE Beyond Design Basis Event

BISO Bi-structural Isotropic

CDF Core Damage Frequency

CFR Code of Federal Regulation

COL Combined License

DBA Design Basis Accident

DBE Design Basis Event

DOE Department of Energy

EAB Exclusion Area Boundary

EPA Environmental Protection Agency

FOA Funding Opportunity Announcement

FRG Federal Republic of Germany

FSV Fort St. Vrain

FY Fiscal Year

GA General Atomics

HPB Helium Pressure Boundary

HPS Helium Purification System

HTGR High-Temperature Gas-Cooled Reactor

HTR High-Temperature Reactor

HTTR High Temperature Engineering Test Reactor

HVAC Heating, Ventilation, and Air Conditioning

INET Institute of Nuclear and New Energy Technology

IPyC Inner Pyrocarbon

JAEA Japan Atomic Energy Agency

kW Kilowatt

LBE Licensing Basis Event

LERF Large Effluent Release Frequency

LEU Low Enriched Uranium

LWR Light Water Reactor 


$\begin{array}{ll}\text { MHTGR } & \text { Modular High-Temperature Gas-Cooled Reactor } \\ \text { MW } & \text { Megawatt } \\ \text { MW(t) } & \text { Megawatt Thermal } \\ \text { MW(e) } & \text { Megawatt Electric } \\ \text { NGNP } & \text { Next Generation Nuclear Plant } \\ \text { NRC } & \text { Nuclear Regulatory Commission } \\ \text { OECD } & \text { Organization for Economic Cooperation and Development } \\ \text { OPyC } & \text { Outer Pyrocarbon } \\ \text { PAG } & \text { Protective Action Guide } \\ \text { PBMR } & \text { Pebble Bed Modular Reactor } \\ \text { PCRV } & \text { Prestressed Concrete Reactor Vessel } \\ \text { PRA } & \text { Probabilistic Risk Assessment } \\ \text { PyC } & \text { Pyrocarbon } \\ \text { R/B } & \text { Release Rate-to-Birth Rate Ratio } \\ \text { R\&D } & \text { Research and Development } \\ \text { RCCS } & \text { Reactor Cavity Cooling System } \\ \text { SiC } & \text { silicon carbide } \\ \text { SSCs } & \text { Structures, Systems, and Components } \\ \text { SC-MHR } & \text { Steam-Cycle Modular Helium Reactor } \\ \text { SG } & \text { Steam Generator } \\ \text { THTR } & \text { Thorium High-Temperature Reactor } \\ \text { TLRC } & \text { Top-Level Regulatory Criteria } \\ \text { TRISO } & \text { Tri-structural Isotropic } \\ \text { UK } & \text { United Kingdom } \\ \text { U.S. } & \text { United States } \\ & \end{array}$




\section{Modular HTGR Safety Basis and Approach 1. INTRODUCTION}

The Next Generation Nuclear Plant (NGNP) project was formally authorized by the Energy Policy Act of 2005 [EPAct 2005]. High-Temperature Gas-Cooled Reactor (HTGR) technology was selected for the NGNP project because it can provide both electricity and high temperature heat needed for industrial processes and because the HTGR's inherent safety that allows it to be uniquely coupled to industrial applications. Nuclear Regulatory Commission (NRC) licensing of the NGNP plant will demonstrate the efficacy for licensing future HTGRs for commercial industrial applications. As one of the Generation IV reactor designs, the HTGR has traded enhanced safety and less reliance on engineered safety systems for some of the economies of scale and other cost optimizations present in the latest generation of Light Water Reactors (LWRs). HTGR technology is expected to supply process heat as an alternative to existing carbon-based energy sources in commercial applications. These potential applications include cogeneration of electricity and steam supply or high temperature gas supply to petrochemical and refining plants, electricity and steam supply for oil recovery from oil sands, and high temperature steam or gas and electricity for hydrogen production. Applied in this way, HTGR technology can significantly reduce the use of fossil fuels for the production of process heat and reduce greenhouse gas releases.

The primary purpose of this information paper is to provide a summary level introduction to the HTGR safety basis and approach to ensure public safety. The discussion of the HTGR safety basis and approach covers HTGR history, public safety objectives, inherent and passive safety features, radionuclide release barriers, functional safety approach, and risk-informed safety approach. This paper is intended to provide the Nuclear Regulatory Commission (NRC) staff and public stakeholders with a fundamental understanding of the HTGR concept, how the safety approach meets public safety requirements, and how the approach differs from typical LWRs.

The scope of this information paper is primarily focused on offsite public safety. Security and onsite worker safety are only covered to the extent that the characteristics and features of the HTGR might contribute to these important objectives.

The information in this paper is intended to further the NRC staff and public stakeholders understanding of the modular HTGR safety approach. The NGNP project is not requesting any NRC action or specific feedback on this information paper because other white papers are addressing key generic issues associated with priority licensing topics in greater detail. 


\section{MODULAR HTGR HISTORY}

Appendix A describes the history of the international development of High Temperature Gas-Cooled Reactors (HTGRs) from the 1950s to the 1980s. Modular HTGR development began in the 1980s and is described in this section

In the 1980s, HTGR designers at the German company INTERATOM, under license to HRB, the designer of the AVR and THTR, developed a new pebble bed design that modified the reactor system in such a way that the residual heat could be removed passively under all circumstances, and the need for active emergency core cooling systems could be eliminated. The resulting design was called the HTR Module [NED 1984]. For typical reactor designs, the reactor core height and diameter are almost equal for neutron economy reasons. However, in the HTR Module, the core height was three times larger than the diameter. The advantage of this core geometry is that the residual heat can be removed radially and fully passively from an uninsulated reactor vessel. The disadvantages are increased neutron leakage and a higher core flow resistance. The HTR Module was not intended exclusively for electricity production, but other possible missions were envisioned as well, including heat and power cogeneration, process heat and/or steam production, and district heating.

The U.S. modular HTGR concept began in 1984 when Congress challenged the HTGR industry to investigate the potential for using HTGR technology to develop a "simpler, safer" nuclear power plant design. The goal was to develop a passively safe HTGR plant that was also economically competitive. To maintain the coated-particle fuel temperatures below damage limits during passive decay heat removal, the core's physical size had to be limited; the maximum reactor power capacity was found to be about 200 $\mathrm{MW}(\mathrm{t})$ for a solid, cylindrical core geometry. However, this rating was projected to not be economically competitive for electric power generation. This judgment led to the development of an annular core concept to enable larger cores with increased power capacity. DOE and General Atomics developed a 350 MW(t) Modular High Temperature Gas-Cooled Reactor (MHTGR) using an annular prismatic block core arrangement. Licensing activities included preapplication interaction with the NRC and submittal of numerous documents including a Preliminary Safety Information Document [DOE 1992]. The annular core design was later applied to the pebble bed core.

Since the early 1980s, HTGR designs applying the pebble bed and prismatic reactor fuel designs have been developed by the U.S., Russia, South Africa, France, Germany, China, Korea, and Japan. Japan and China have each built and are operating test reactors - the Chinese built the pebble bed-based HTR-10 and the Japanese built the prismatic-based High Temperature Engineering Test Reactor (HTTR).

The first HTGR constructed in Japan is the HTTR constructed at the Oarai Research and Development Center of the Japan Atomic Energy Agency (JAEA). The reactor thermal power is $30 \mathrm{MW}$. The reactor outlet temperature is $850{ }^{\circ} \mathrm{C}$ in rated operation mode and $950{ }^{\circ} \mathrm{C}$ in high temperature test operation mode. The first criticality of the HTTR was achieved in 1998. First operation of the high temperature test operation mode was achieved in 2004. Safety demonstration tests have been performed in HTTR, and more are planned. Results of long-term high-temperature operation have proven stable reactor operation. The test results have also demonstrated that the HTTR is able to supply stable hightemperature heat to heat utilization systems such as thermo-chemical hydrogen production [HTR 2010].

In 1992, China decided to construct the $10 \mathrm{MW}(\mathrm{t})$ high-temperature gas-cooled test reactor (HTR-10) at the Institute of Nuclear and New Energy Technology (INET) site in Beijing. The HTR-10 achieved its first criticality in December 2000 and was successfully connected to the electric grid in January 2003. From April 2003 to September 2006, INET completed four experiments to confirm and verify inherent safety features of modular HTRs [NED 2009]:

- loss of offsite power without any counter-measures,

- main helium blower shutdown without any counter-measures, 
- loss of main heat sink without any counter-measures, and

- withdrawal of all control rods without any counter-measures.

The success of the HTR-10 R\&D program convinced the Chinese to start plans to commercialize the pebble bed technology in 2001. The HTR-PM is designed as two $250 \mathrm{MW}(\mathrm{t})$ reactor modules coupled with two steam generators, which are connected to one steam turbine-generator of $210 \mathrm{MW}$ electric power. The core inlet temperature was chosen to be $250{ }^{\circ} \mathrm{C}$ while the outlet temperature is $750{ }^{\circ} \mathrm{C}[\mathrm{NED}$ 2009].

In FY-06, the DOE initiated the NGNP Project at INL as directed by the 2005 Energy Policy Act. The objective of the NGNP Project is to demonstrate the HTGR technology to produce electricity and high temperature heat. In FY-07, preconceptual designs of pebble bed and prismatic based plants were developed by Westinghouse Electric Company, LLC, and Pebble Bed Modular Reactor (PBMR) Pty Ltd. from South Africa, AREVA NP, Inc., and General Atomics. These plants were designed for production of electricity and hydrogen with reactor ratings that varied from 500 to $600 \mathrm{MW}(\mathrm{t})$ and reactor outlet temperatures of 900 to $950{ }^{\circ} \mathrm{C}$. Subsequent to the preconceptual design work, significant interaction with potential industrial end users of the HTGR technology and completion of trade studies concluded that the HTGR should be viewed as a source of high-temperature process heat that can be used to meet the energy needs of industry in several forms such as electricity, steam, high-temperature gas, hydrogen, and oxygen. This work has reduced the reactor core outlet temperature and refined the configurations and operating conditions of the pebble bed and prismatic-reactor-based plants to ensure they meet the energy needs of industry.

On September 18, 2009, the Department of Energy issued a funding opportunity announcement (FOA) for the development of the conceptual design of the NGNP. On November 16, 2009, the Department received several applications that were evaluated by an independent review team of nuclear reactor professionals and by a federally staffed review panel that advised the selection official. The resulting selections were announced in March 2010 [INL 2010e]. A cooperative agreement was put in place with the General Atomics (GA) team to perform conceptual-level design work for the NGNP Project based on the prismatic block reactor concept. The GA team prepared a Conceptual Design Report containing a summary-level description of their 350-MW(t) Steam-Cycle Modular Helium Reactor (SCMHR) Demonstration Plant. The SC-MHR has a nominal reactor outlet helium temperature of $725^{\circ} \mathrm{C}$ and is designed to produce steam at $585^{\circ} \mathrm{C}$ and $16.5 \mathrm{MPa}$ at the exit of the steam generator [GA 2010].

Figures 1 and 2 illustrate the SC-MHR general plant arrangement and plant configuration, respectively.

Additionally, AREVA NP completed a pebble bed reactor design assessment based on the existing HTR module design. 


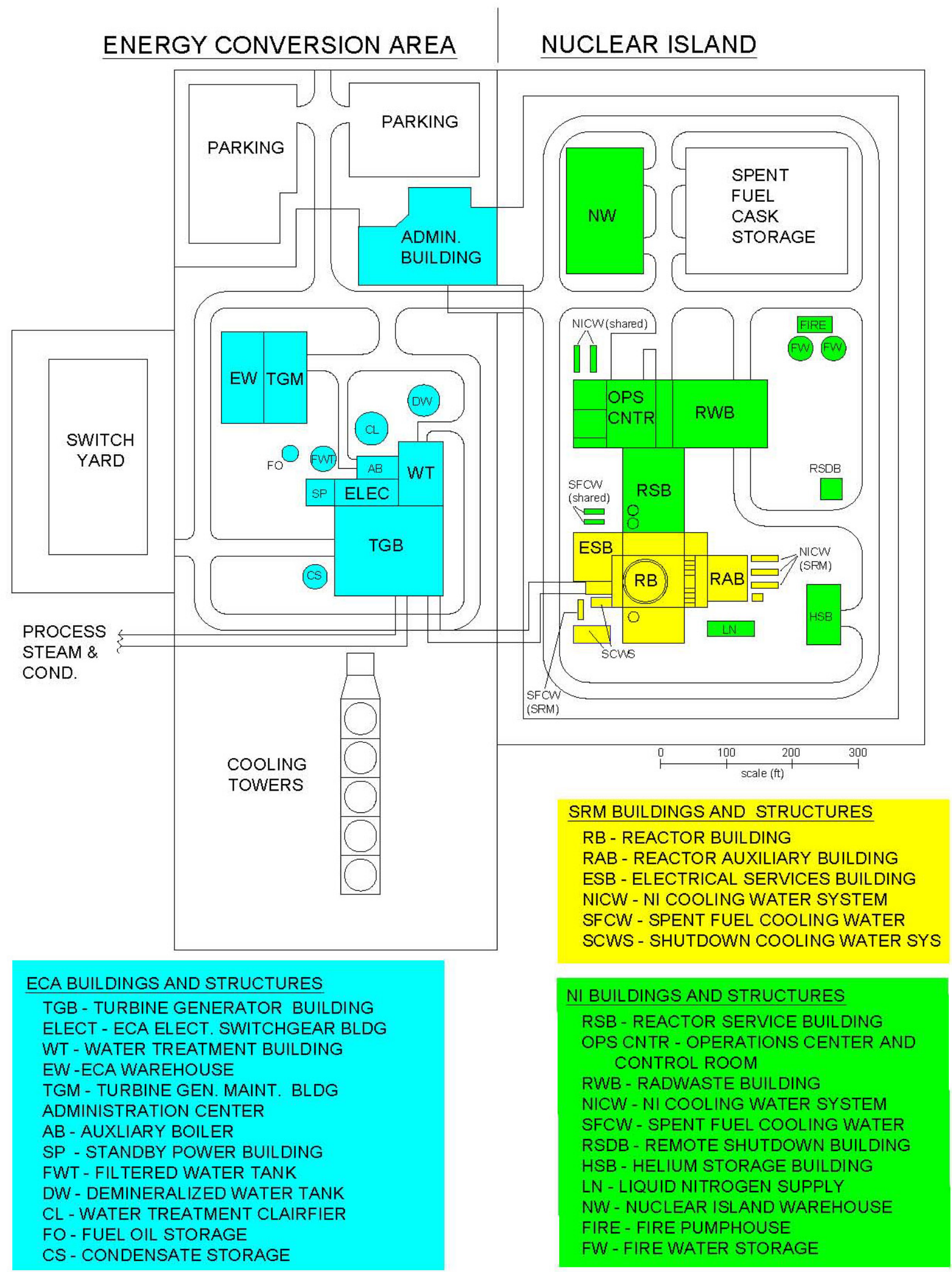

Figure 1. SC-MHR demonstration plant general arrangement. 


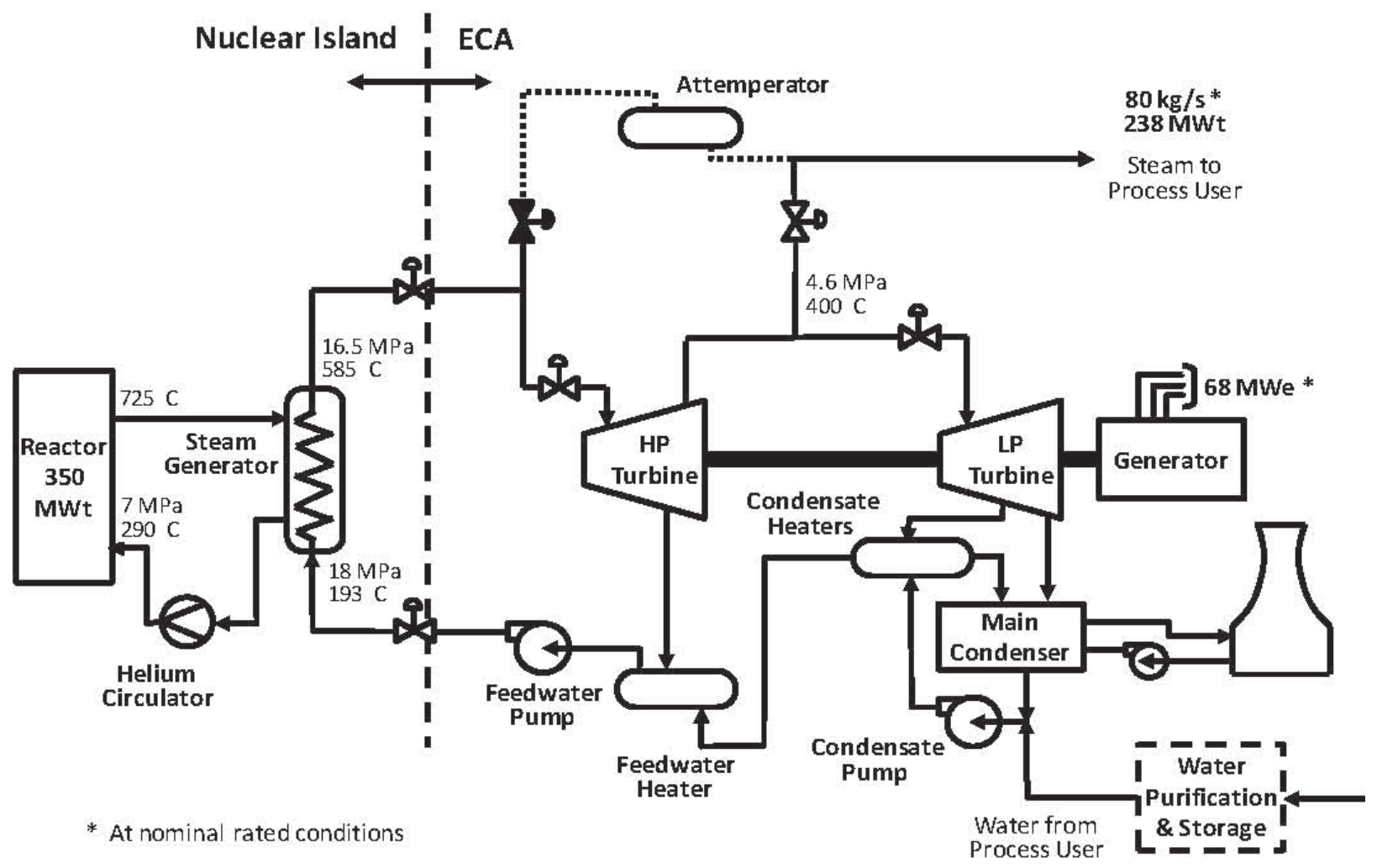

Figure 2. SC-MHR demonstration plant configuration. 


\section{SAFETY OBJECTIVES}

The primary safety objective of the NGNP design is to limit the dose from accidental releases so that regulatory requirements for protection of the health and safety of the public are met at an exclusion area boundary $(\mathrm{EAB})$ that is no more than a few hundred meters, (e.g., $400 \mathrm{~m}$ ), from the reactor. To eliminate the need for public evacuation or sheltering beyond the site boundary, the NGNP design goal is to meet the Environmental Protection Agency (EPA) plume exposure Protective Action Guides (PAGs) [EPA 1992] at the EAB.

Existing LWR technical licensing requirements assure adequate public safety through a set of criteria from the NRC regulations and guidance. These requirements were developed and have been traditionally applied to licensing of LWRs. There are significant differences in the HTGR technology and safety basis from those of the LWRs which require interpretation of the NRC regulations. Additionally, these regulations were traditionally applied on a prescriptive basis during initial licensing of current LWRs. There has been a general trend, however, in NRC oversight of operating LWRs toward a risk-informed performance based process. The NRC has assessed the advantages of applying this approach to the licensing of new and advanced nuclear technologies and has concluded that such a process appears to have merit and should be applied to the licensing of the NGNP demonstration plant [NRC 2008]. This was also the licensing approach recommended by the NRC \& DOE in developing the licensing strategy for NGNP [DOE/NRC, 2008]. Accordingly, the licensing and safety basis for the NGNP demonstration plant is being developed using a risk-informed, performance-based technical approach that adapts existing NRC licensing requirements in establishing NGNP design-specific licensing requirements. As part of the process of risk-informing regulatory compliance, top-level regulatory criteria (TLRC) are identified from NRC regulations and guidance that establish dose limits on consequences from licensing basis events (LBEs) to assure public safety [INL 2010c]. The TLRC are based on the following objectives:

1. Provide direct public health and safety acceptability limits in terms of individual radiological consequences

2. Be independent of HTGR reactor type and site

3. Provide well-defined, quantifiable risk criteria

The following primary sources have been identified as containing criteria that establish limits on the risk or consequences of potential radiological releases from nuclear power plants in the U.S.

- Reactor Safety Goal Policy Statement [NRC 1986]: This policy statement limits public risk resulting from nuclear power plant operation. Limits are stated in the form of the maximum allowable risk of immediate death and the risk of delayed mortality from exposure to radiological releases of all types from nuclear power plants.

- 10 CFR Part 20, "Standards for Protection against Radiation (Subpart D, Radiation Dose Limits for Individual Members of the Public)": These criteria limit the dose consequences of releases associated with relatively high frequency events that occur as part of normal plant operations.

- $\quad 10$ CFR 50.34(a)(ii)(D), "Contents of Applications: Technical Information (Radiological Dose Consequences)": This section of the regulation specifies dose limits for evaluating the acceptance of the engineered safety features that are intended to mitigate the radiological consequences of accidents.

Frequency consequence criteria from these guidelines are used to represent the TLRC for judging the acceptability of the frequency and consequence of each LBE. Figure 3 depicts the frequency-consequence curve developed for the NGNP Project based on these guidelines which assures adequate protection of public safety [INL 2010c]. 


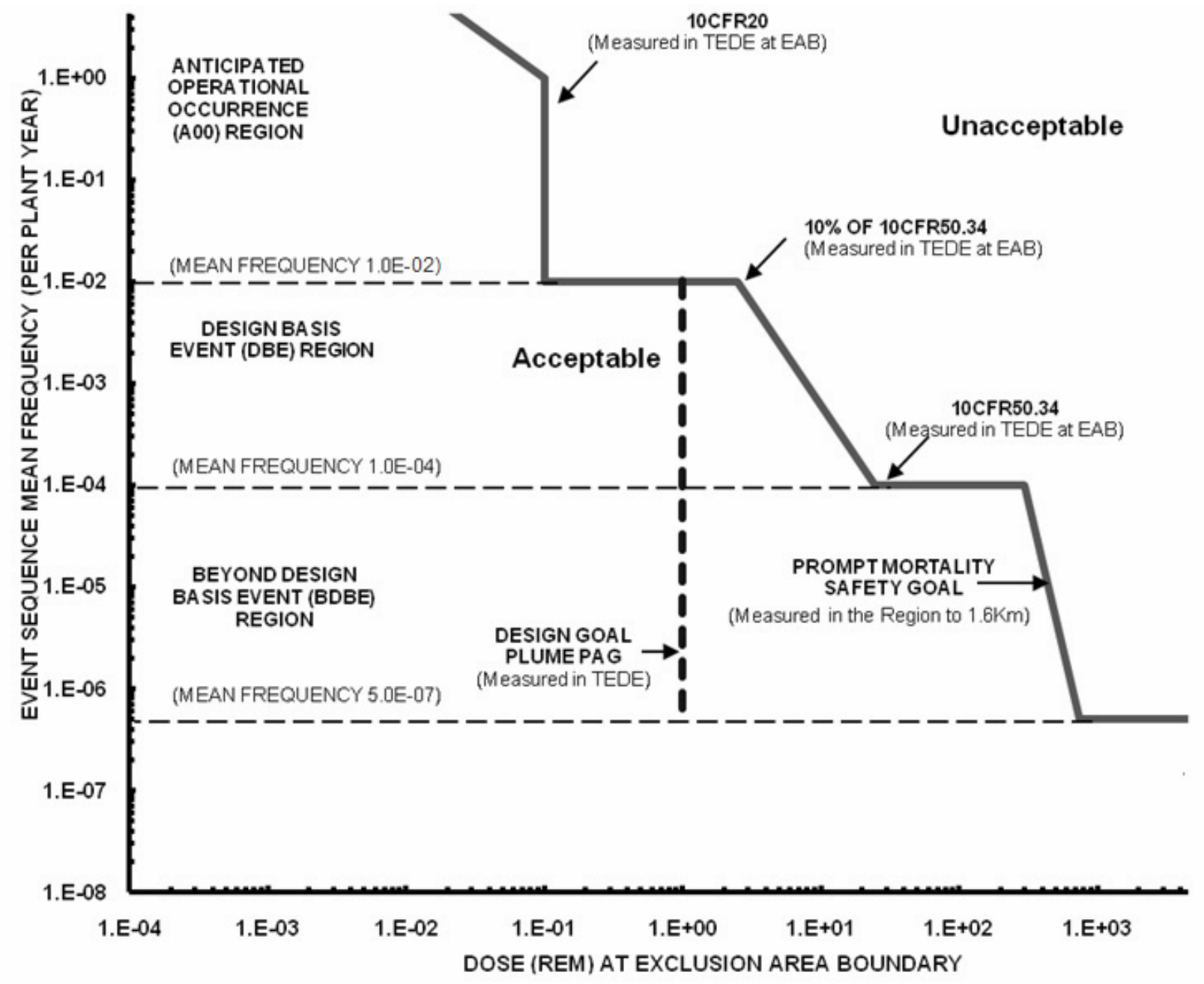

Figure 3. NGNP frequency-consequence curve. 


\section{INHERENT AND PASSIVE SAFETY FEATURES}

To achieve the safety objectives for the NGNP Project, the HTGR relies on inherent and passive safety features. Modular HTGRs use the inherent high temperature characteristics of TRISO-coated fuel particles, graphite moderator, and helium coolant, along with passive heat removal capability of a lowpower-density core with a relatively large height-to-diameter ratio within an uninsulated steel reactor vessel to assure sufficient core residual heat removal under loss-of-forced cooling or loss-of-coolantpressure conditions.

The primary radionuclide retention barrier in the HTGR consists of the three ceramic coating layers surrounding the fissionable fuel kernel to form a fuel particle. As shown in Figure 4, these coating layers include the inner pyrocarbon (IPyC), silicon carbide ( $\mathrm{SiC})$, and outer pyrocarbon (OPyC), which together with the buffer layer constitute the TRISO coating. The coating system constitutes a miniature pressure vessel that has been engineered to provide containment of the radionuclides and gases generated by fission of the nuclear material in the kernel. Thousands of these TRISO-coated particles are bonded in a carbonaceous material into either a cylindrical fuel compact for the prismatic HTGR or a spherical fuel element for the pebble bed HTGR. These fuel particles can withstand extremely high temperature without losing their ability to retain radionuclides under all accident conditions. Fuel temperatures can remain at $1600^{\circ} \mathrm{C}$ for several hundred hours without loss of particle coating integrity [INL 2010a]. This high temperature radionuclide retention capability is the key element in the design and licensing of HTGRs.

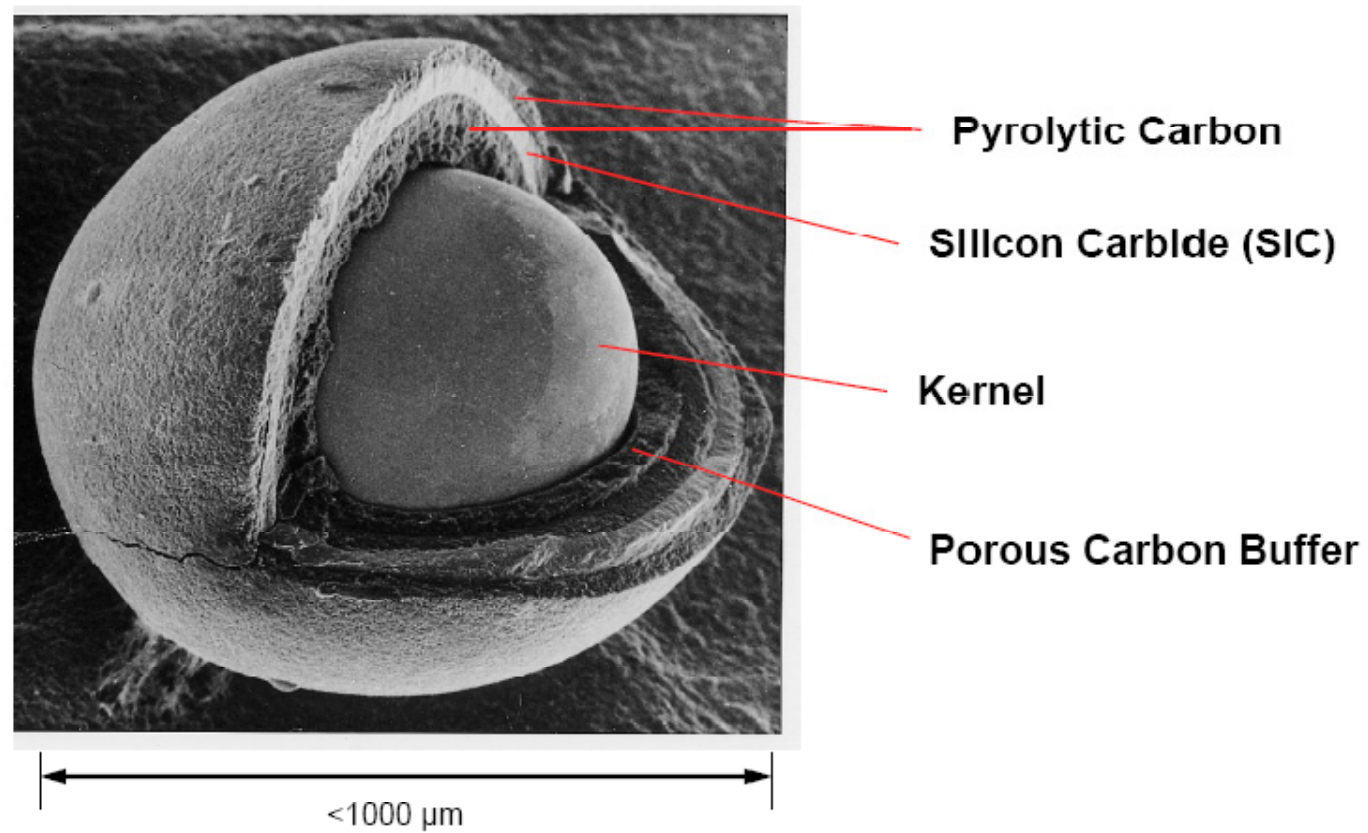

Figure 4. TRISO-Coated Fuel Particle Cross Section.

Graphite can withstand even higher temperatures than the fuel without structural damage, which complements the fuel's high temperature capability. Massive graphite structures in the core provide extremely large heat capacity. The high heat capacity and low power density of the core result in very slow and predictable temperature transients. In addition, the strength of graphite increases with temperature over the full range of temperatures applicable to the HTGR. The long mean free path of neutrons in graphite provides a neutronically stable core. The graphite also holds up certain radionuclides, further reducing potential release from the core.

Helium is chemically inert and neutronically transparent, meaning it will not aggravate an accident by participating in any chemical or nuclear reaction. Helium will not change phase in the reactor; therefore, it 
is impossible to have the problem of two phase flow within the reactor, which would affect reactivity and temperature control. The use of helium minimizes the problems of primary system corrosion and greatly reduces the resultant buildup of radioactive byproducts associated with water-cooled reactors.

Modular HTGRs are designed to passively remove residual and decay heat from the core regardless of whether the primary coolant is present. Passive heat removal is possible due to the large thermal margins, low power density, and core configuration. A relatively large length-to-diameter ratio of the core provides a large surface area for heat removal from the uninsulated steel reactor vessel. The concrete walls surrounding the reactor vessel are covered by panels that remove the heat radiating from the reactor vessel. These panels are a key part of the Reactor Cavity Cooling System (RCCS) used in modular HTGR designs. The RCCS can either be air-cooled or water-cooled. Either design has a passive cooling capability that does not rely on electric power.

The large negative temperature coefficient of modular HTGRs, along with their large thermal margins, provide for an inherent shutdown capability to deal with failures to scram the reactor as demonstrated in AVR and HTR-10 testing. Gravity-driven and diverse reactivity control systems provide further confidence of the ability to shutdown the reactor. The low power density, large heat capacity, and large thermal margins also allow the reactor to reach as high as $200 \%$ power during reactivity insertion accidents without significant changes in fuel temperature.

No AC powered safety-related systems and no operator actions are required to respond to any of the accident scenarios that have been postulated for the modular HTGRs throughout their licensing history. 


\section{RADIONUCLIDE RELEASE BARRIERS}

The five barriers to radionuclide release that form a functional containment system for modular HTGRs are as follows:

1. The fuel particle kernel,

2. The fuel particle coatings (silicon carbide and pyrocarbon coatings),

3. The core graphite and carbonaceous materials,

4. The helium pressure boundary, and

5. The reactor building.

The effectiveness of these barriers in containing radionuclides depends upon a number of factors including the chemistry and half-lives of the various radionuclides, the service conditions, and irradiation effects. The effectiveness of these release barriers is also event specific.

\subsection{Fuel Particle Kernel}

The first barrier to radionuclide transport and release is the fuel kernel itself. Under normal operating conditions, the kernel retains a substantial fraction (>95\%) of the radiologically important, short-lived fission gases such as $\mathrm{Kr}-88$ and I-131. However, at elevated temperatures the effectiveness of the fuel kernels for retaining fission gases can be reduced to a retention of $80-90 \%$ at the peak temperature locations [Martin 1993].

The release of short-lived fission gases from heavy-metal contamination and from fuel kernels is typically expressed in terms of the release rate-to-birth rate ratio $(\mathrm{R} / \mathrm{B})$. At steady state, the $\mathrm{R} / \mathrm{B}$ ratio is numerically equal to the fractional release. The fission gas release models give the R/Bs from heavymetal contamination, bare kernels, and from failed particles under irradiation as a function of chemical element, isotope half-life, temperature, and burnup. These functional dependencies are determined experimentally.

Metallic fission products such as silver, cesium, palladium and perhaps other noble metals are diffusively released to a significant degree from the small percentage of fuel kernels at the upper end of the range of normal operating temperatures (typically $>1100-1200{ }^{\circ} \mathrm{C}$ ). The other fission metals, including radiologically important $\mathrm{Sr}-90$, are only released from the kernel by fission recoil at normal operating temperatures. Under elevated temperature conditions, the retention in fuel kernels of long-lived, volatile fission metals such as $\mathrm{Cs}, \mathrm{Ag}$, and $\mathrm{Sr}$ is strongly dependent on temperature and burnup.

Fractional releases of fission gases from exposed fuel kernels under irradiation can be enhanced if the kernel is hydrolyzed by reaction with water vapor, which may be present in the helium coolant (e.g., because of a tube leak in a steam generator located in the primary helium loop). The magnitude of the effect depends upon the kernel composition, with $\mathrm{UC}_{2}$ showing the largest enhancement and $\mathrm{UO}_{2}$ showing the least. The effect for UCO is intermediate. With kernels containing uranium carbide, the water reacts to convert the carbide phase completely to oxide along with kernel swelling and increased porosity. With $\mathrm{UO}_{2}$ kernels, a hyperstoichiometric uranium oxide phase may be formed. In any case, kernel porosity is increased with enhanced fission gas release [INL 2010b].

The extensive international database on the radionuclide release from fuel kernels has been summarized in numerous review documents [IAEA 1997, Martin 1993, Hanson 2004].

\subsection{Fuel Particle Coatings}

The second and most important barrier to radionuclide release from the core, particularly during accidents, is the silicon carbide and pyrocarbon coatings of each fuel particle. Both the $\mathrm{SiC}$ and PyC coatings provide a barrier to the release of fission gases. The SiC coating acts as the primary barrier to the 
release of metallic fission products because of the low solubilities and diffusion coefficients of fission metals in SiC. The PyC coatings are partially retentive of $\mathrm{Cs}$ at lower temperatures but provide little holdup of $\mathrm{Ag}$ and $\mathrm{Sr}$ [INL 2010a].

Coated particle in-service failure or degradation can entail failure of both the PyC layers and the $\mathrm{SiC}$ layer resulting in an exposed kernel (particle failure), or degradation of only the $\mathrm{SiC}$ layer such that the remaining intact $\mathrm{PyC}$ layers continue to retain fission gases. In-service failures are primarily due to manufacturing defects such as a thin or missing buffer layer.

There are considerable international data on the transport of fission products in the $\mathrm{SiC}$ and $\mathrm{PyC}$ coatings of TRISO fuel particles (e.g., IAEA 1997). At accident temperatures, most of these data were obtained by heating irradiated particles and effective diffusion coefficients were deduced from the observed time histories of fission product release. At temperatures typical of temperatures during normal operation, data was obtained from irradiations

\subsection{Core Graphite and Carbonaceous Materials}

For a prismatic core, the fuel compact matrix and the fuel block graphite collectively are the third fission product transport and release barrier. For a pebble bed core, the analog is the pebble matrix, including the unfueled outer shell of the spherical pebble fuel element. Radionuclide transport in fuel matrix and fuel element graphite is treated collectively since the experimental techniques to characterize radionuclide transport in them are the same, and the radionuclide transport mechanisms appear to the same based on available data [INL 2010b].

The fuel matrix material is a relatively porous carbonaceous material and provides little holdup of the fission gases that are released from the fuel particles. The effect is generally neglected in calculations of fission gas transport in the fuel matrix as well as in the fuel block graphite. However, the fuel matrix is a composite material that has a high content of amorphous carbon, and this constituent of the matrix is highly sorptive of metallic fission products, especially strontium, europium, and actinides.

The graphite block of a prismatic fuel element, which is denser and has a more ordered structure than the fuel matrix material, is somewhat less sorptive of the fission metals than the matrix, but it is more effective as a diffusion barrier. The effectiveness of the graphite as a release barrier decreases as the temperature increases. Under typical steam-cycle core conditions, with helium coolant temperatures at the core outlet on the order of $750{ }^{\circ} \mathrm{C}$, the fuel element graphite attenuates the release of Cs from the core by an order of magnitude, and the $\mathrm{Sr}$ is essentially completely retained. The extent to which the graphite attenuates Ag release is less well characterized, and there is some evidence that the retention of $\mathrm{Ag}$ by graphite increases as the total system pressure increases, implying gas phase transport through the interconnected pore structure of the graphite. Fission metals that escape the core in either a prismatic or pebble bed reactor will be sorbed into upper and lower graphite reflectors in addition to being deposited onto metallic surfaces as the primary coolant circulates through the system.

The international database for radionuclide transport in matrix and graphite has been summarized previously (e.g., Hoinkis 1983, IAEA 1997). The database for nuclear graphite is large in recognition of its effectiveness as a release barrier in HTGR cores. Only cesium and silver nuclides effectively migrate through the fuel element graphite at normal operating temperatures. The other fission metals, including strontium, europium, and the actinides, are completely retained by the graphite during normal operation. A fraction of the strontium and europium is released under core heat-up peak temperature conditions, but the actinides are still completely retained. Events entailing ingress of moisture into the reactor can result in limited graphite oxidation and mobilization of fission products contained in the oxidized graphite. However, as discussed in Section 6.3, measures are taken to limit these effects. 


\subsection{Helium Pressure Boundary}

The fourth transport and release barrier is the helium pressure boundary (HPB), which contains the primary circuit. Once the fission products have been transported from the core into the coolant, they are transported throughout the primary circuit by the helium coolant. Although the primary purpose of the helium purification system (HPS) is to control chemical impurities in the helium, the HPS efficiently removes both gaseous and metallic fission products from the helium at a rate determined by the gas flow rate through the purification system [INL 2010b].

For the condensable fission products, the dominant removal mechanism is deposition ("plateout") on the various helium-wetted surfaces in the primary circuit (i.e., the plateout rate far exceeds the purification rate). The plateout rate is determined by the mass transfer rates from the coolant to the fixed surfaces, by the sorptivities of the various materials of construction for the volatile fission products, and by the temperatures of the surfaces. Condensable radionuclides may also be transported throughout the primary circuit sorbed on particulates ("dust"), which may be present in the primary circuit. The distribution of these contaminated particulates may be considerably different from the distribution of radionuclides transported as atomic species.

The circulating, dust, and plateout activities in the primary circuit are potential sources of release to the environment in the event of helium leaks or as a result of the venting of helium in response to over pressurization of the primary circuit (e.g., in response to significant water ingress because of a steam generator tube leak in a steam cycle plant). The fraction of the circulating activity lost during such events is essentially the same as the fraction of the helium that is released, although the radionuclide release can be mitigated by pump down through the HPS if the leak rate is sufficiently slow.

A small fraction of the plateout near the leak location may also be re-entrained, or "lifted off," and a small fraction of the dust may be re-suspended, if the rate of depressurization is sufficiently rapid. The amount of fission product liftoff is expected to be influenced by the amount of dust in the primary circuit as well as by the presence of friable surface films on primary circuit components, which could possibly spall off during a rapid depressurization.

Other mechanisms that can potentially result in the removal and subsequent environmental release of primary circuit plateout activity are "steam-induced vaporization" and "washoff." In both cases, the vehicle for radionuclide release from the primary circuit is water that has entered the primary circuit. In principle, both water vapor and liquid water could partially remove plated out radionuclides. However, even if a fraction of the plated out radionuclides is removed from the fixed surfaces, there would be environmental release only in the case of venting of helium/steam from the primary circuit. For all but the largest water ingress events, the pressure relief valve does not lift. Moreover, the radiologically important

nuclides, such as iodine and cesium, are expected, based on available data, to remain preferentially in the liquid water that remains inside the primary circuit.

Figure 5 shows the SC-MHR reactor system and Figure 6 shows the pebble bed primary circuit. 


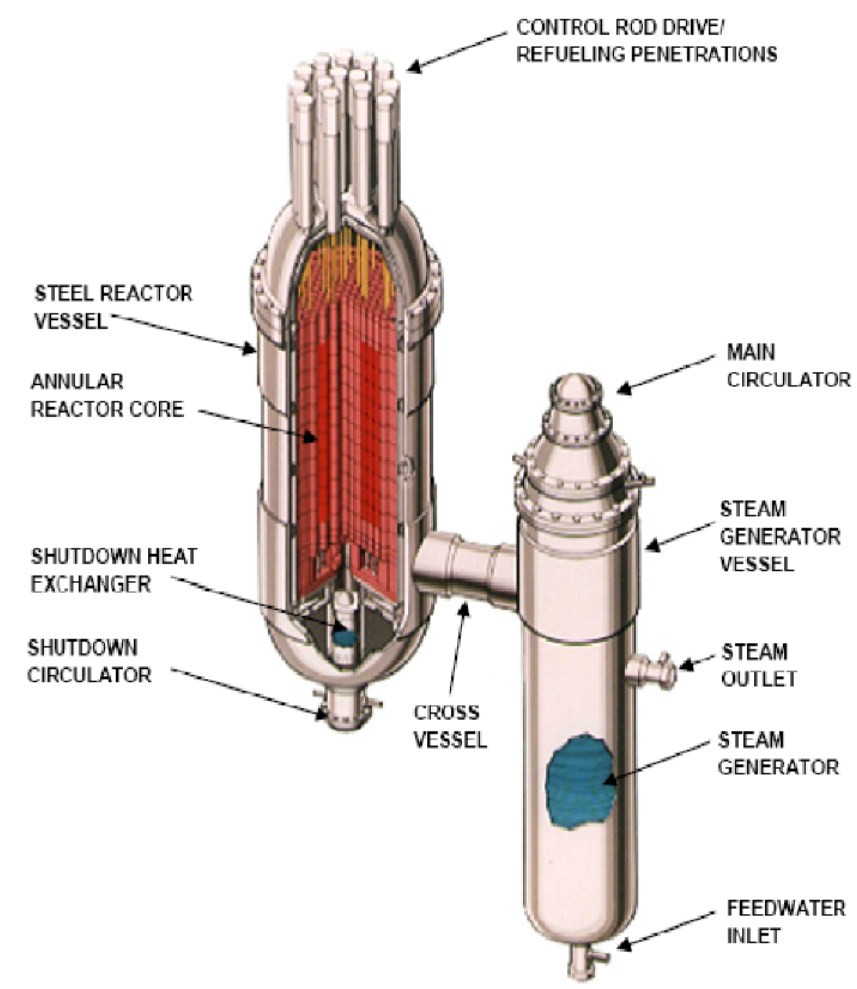

Figure 5. SC-MHR reactor system.

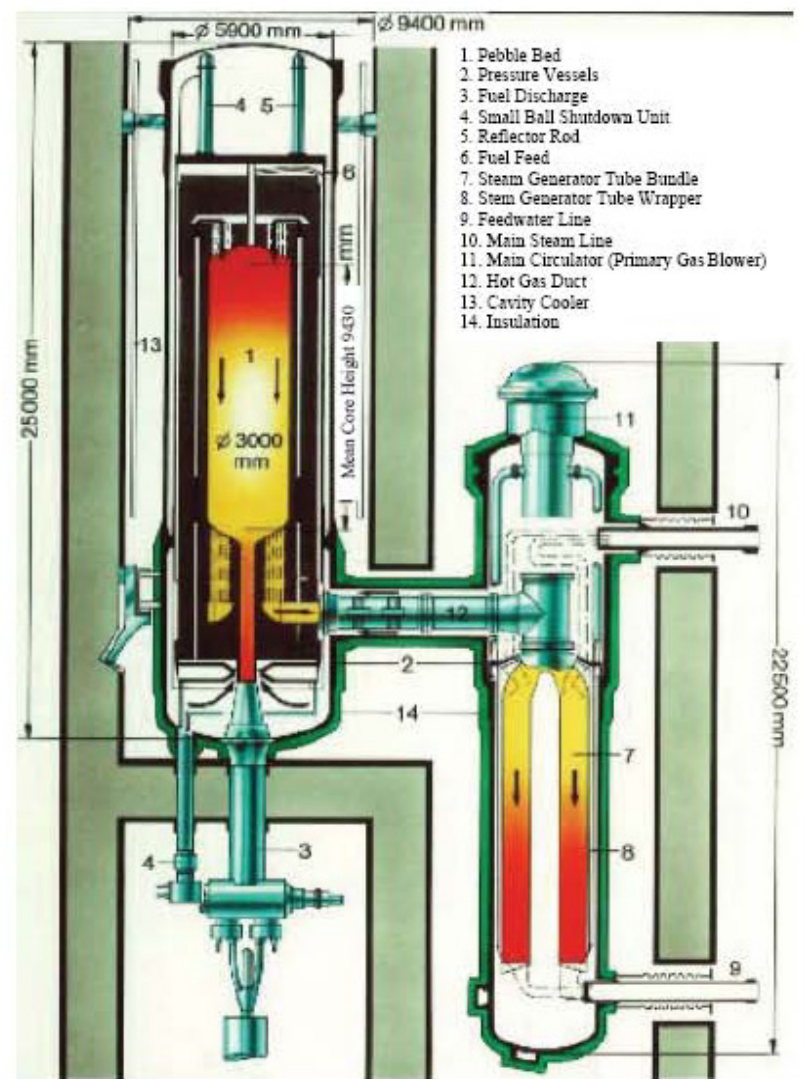

Figure 6. Pebble bed HTR-module primary circuit. 


\subsection{Reactor Building}

The reactor building is the fifth and final barrier to the transport and release of radionuclides to the environment. Its effectiveness as a release barrier is highly event specific. Typically, a vented low pressure reactor building is the baseline design for both prismatic and pebble bed modular HTGRs. Retention of radionuclides in the reactor building is influenced by several factors, including the extent to which the design of the building is compartmentalized, by the action of the reactor building HVAC system, the action of the building overpressure relief system, and reactor building leakage [INL 2010b].

In the event of rapid depressurization transients, louvers in the reactor building open, and a significant portion of the released helium coolant is vented to the environment until the pressure in the reactor building is reduced to near atmospheric pressure, at which time the louvers close. Consequently, radionuclide retention in the reactor building is limited for rapid depressurization transients. However, considerable retention is predicted during longer-term core conduction cooldown transients during which forced cooling is unavailable. Under such conditions, the natural removal mechanisms occurring in the reactor building, including condensation, fallout, and plateout, are expected to attenuate the release of condensable radionuclides, including the radiologically important iodine isotopes, by at least an order of magnitude.

The transport behavior of radionuclides during core heat-up accidents in HTGRs is much simpler than that in LWRs. Relatively few radionuclides (primarily, radioisotopes of $\mathrm{Kr}, \mathrm{Xe}, \mathrm{I}, \mathrm{Te}, \mathrm{Ag}, \mathrm{Cs}$ and $\mathrm{Sr}$ ) are released from the core. No heavy metals or core structural materials are released, and the radionuclide mass concentrations are so low that aerosols are not expected to form. Dust present in the primary circuit during normal operation and liftoff of plated out fission products may add to the activity released from the primary circuit into the reactor building during rapid depressurization accidents, but the chemical and physical nature of this material is quite different from LWR aerosols.

Figure 7 illustrates a typical reactor building. The reactor building consists of the structures shown in the figure as being below grade. 


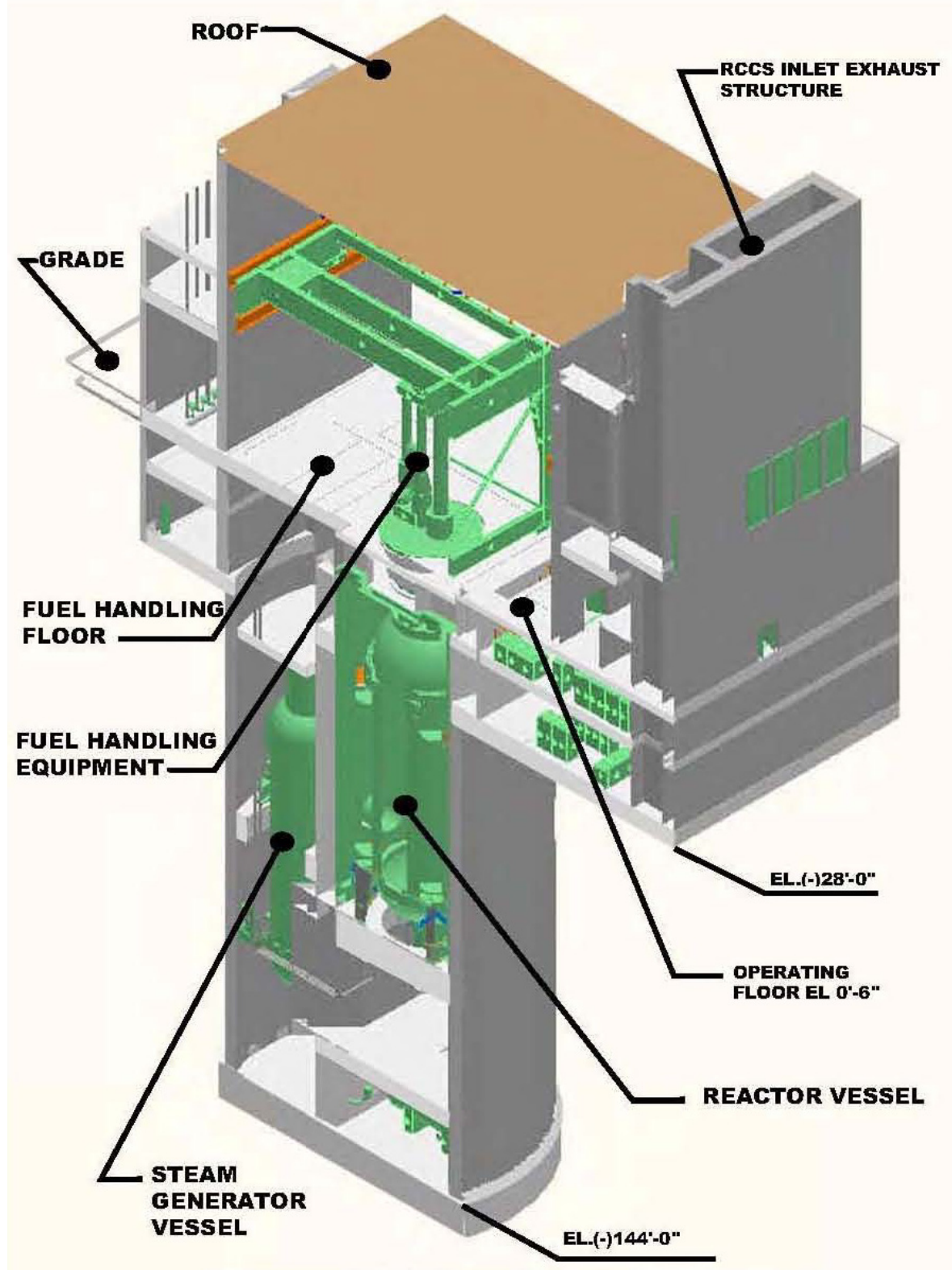

Figure 7. Typical reactor building. 


\section{FUNCTIONAL SAFETY APPROACH}

The safety design approach for the HTGR controls radionuclides primarily at their source within the coated fuel particle during normal operation and during accident conditions without requiring active design features or operator actions. The NGNP safety design approach is framed in terms of reactorspecific safety functions that are developed from the top safety objective of containing the radioactive material and then considering the specific functions that would protect the integrity of the fuel and other radionuclide retention barriers. The required safety functions identified in Figure 8 will keep the consequences of the deterministically-selected Design Basis Accidents (DBAs) within the TLRC offsite dose limits of 10 CFR 50.34 at the EAB. Other safety and special non-safety functions are included in the design to contribute to the plant capabilities for defense-in-depth or to control smaller, nonlimiting sources of radionuclides, and to meet user requirements for plant availability, investment protection, and plume exposure PAGs [INL 2009].

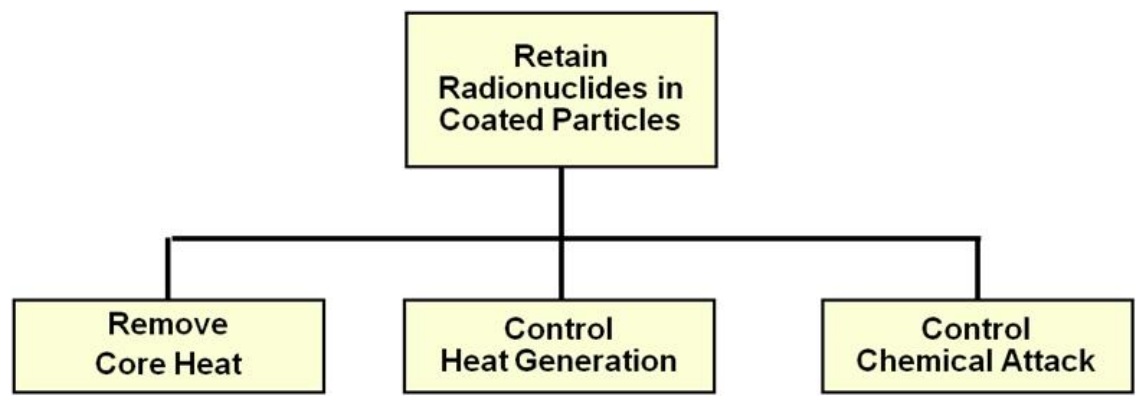

Figure 8. Required safety functions.

Figure 9 illustrates the relationship between various NGNP white papers that provide the details of the elements of the HTGR safety basis. 


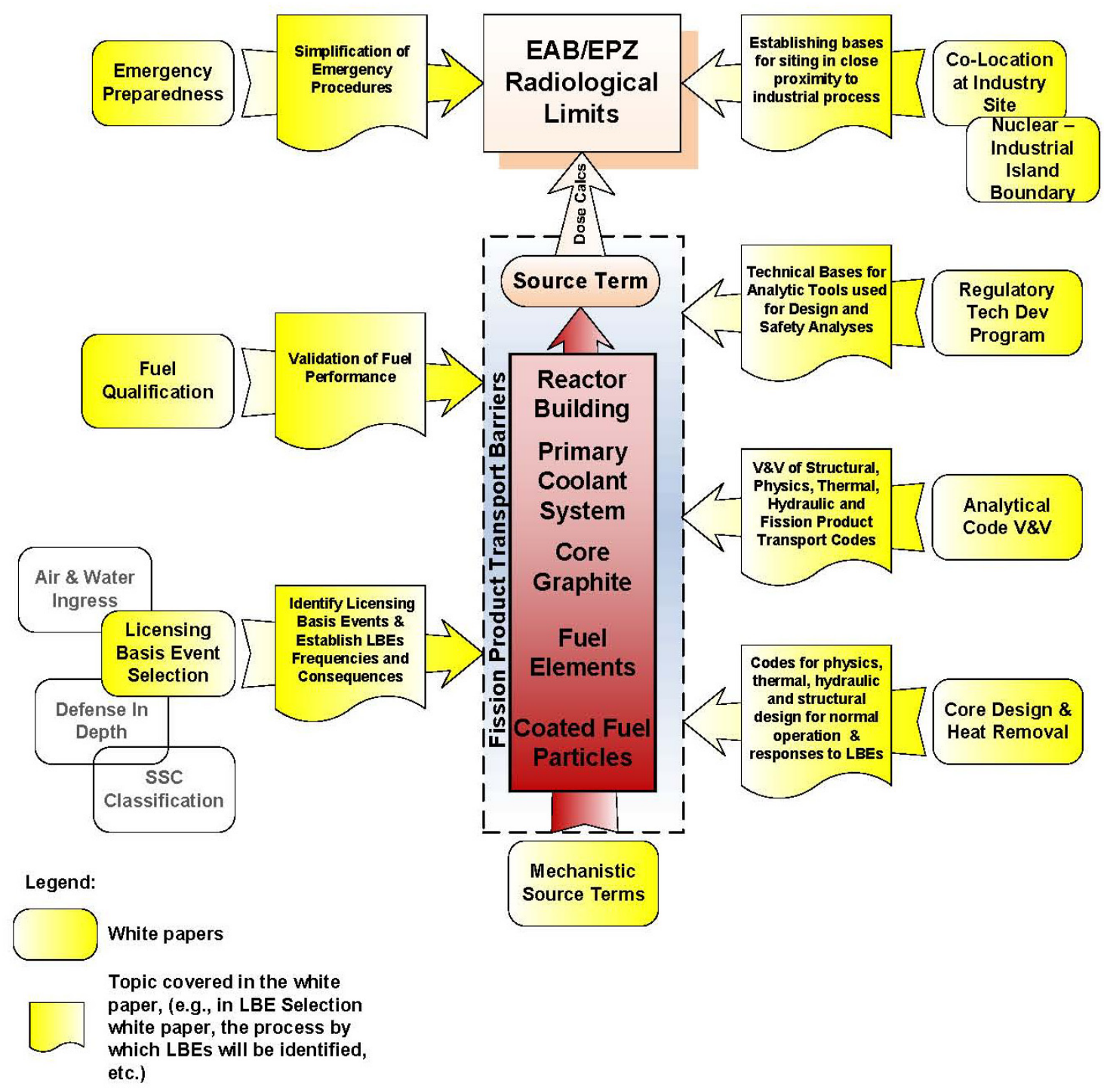

Figure 9. Relationship between NGNP safety basis white papers.

\subsection{Remove Core Heat}

Similar to existing LWRs, HTGRs have multiple methods for accomplishing core heat removal. Reactor cooling can be accomplished by the main loop cooling system, the shutdown cooling system (a non-safety related small circulator and heat exchanger located at the bottom of the reactor vessel), or by passive cooling from the core through the reactor vessel to the RCCS. The shutdown cooling system is designed specifically for residual heat removal in the event that main loop cooling is unavailable. The modular HTGR core is designed so that residual heat removal is not dependent on the primary coolant within the reactor being under pressure for either forced cooling or passive cooling scenarios. Even in the event that all forced cooling systems are unavailable, the core design ensures passive residual heat removal capability. The limited core diameter, limited power density, and unique core assembly configuration (large length-to-diameter ratio) limit core and fuel temperatures during passive cooling with the reactor system pressurized or depressurized. The RCCS, which is independent and diverse from the forced cooling systems, keeps structures, including the reactor building concrete, within allowable temperature limits. The RCCS designs may be either passive or active under normal conditions, but 
always have a passive mode capable of removing residual core heat under accident conditions. Reactor heat is transferred through the reactor vessel walls to the RCCS cooling panels by conduction, natural convection, and radiation heat transfer; the vessel walls are uninsulated to facilitate this process. With RCCS cooling under core heat-up accident conditions, core temperatures peak after about two days at temperatures below that at which significant coated fuel particle degradation can occur, and cool within several days to below normal operation levels.

Even if the RCCS were not available, heat from the reactor vessel walls would be transferred through the inoperable RCCS panels to the concrete walls of the reactor building and ground surrounding the reactor building. This cooling capability is also totally passive. It is not in the design basis and is not necessary to meet any safety requirements or quantitative safety goal, but exists as an ultimate passive feature. With core cooling in this mode, core temperatures peak at about the same level as with RCCS cooling, but the core cools more slowly thereafter and creep deformation of the vessel at the core mid plane is likely to occur after several days [GA 1988].

The vessel system of modular HTGRs has a unique safety function in support of core cooling systems. While containing the helium coolant is an important vessel function for modular HTGRs, "core coverage" by the helium is not required, and sufficient core cooling can be provided even if the helium coolant pressure is lost. The safety function for the vessel system is to provide structural support for the reactor core and to maintain adequate cooling geometry (1) for forced circulation systems, and (2) for radiation and conduction during passive core cooling. Vessel pressure boundary failure is not catastrophic for modular HTGRs if adequate core structural support is maintained to allow passive cooling.

\subsection{Control Heat Generation}

Control of heat generation is accomplished by a very large core negative temperature coefficient and two independent reactivity control systems. Control rods drop by gravity into the core upon loss of electrical power. An automatic positive control action initiated in response to various accidents including reactivity initiated accidents can also cause the rods to drop, or the event itself may cut the power supply. It is an advantage that power is not needed to insert the control rods. In addition, modular HTGRs have a redundant and diverse system (or backup shutdown system) to drop borated graphite pellets by gravity into designated fuel element or reflector channels for reactivity control equivalent to rod insertion. Initiation of the latter system typically requires a positive control signal and an active protection system response.

If both the control rod and backup shutdown systems fail, the temperature coefficient of reactivity will shut down the reactor from any power level following loss of forced cooling. As an example, given that no additional positive reactivity is inserted, core power will be reduced to shutdown levels by negative temperature coefficient alone, such that the RCCS alone can safely cool the core for more than 30 hours after the initial shutdown. Re-criticality due to xenon decay will increase the power and core temperatures to compensate for the loss of negative reactivity until either the control rods or backup shutdown systems have been activated. A test conducted at the AVR in Germany supports analysis which shows that following this initial shutdown, a gradual core temperature increase and negative reactivity addition will occur, with the core stabilizing at a near-zero power level at which the heat generation rate matches the core cooling capability of the passive heat sinks. This is an equilibrium condition that can be maintained indefinitely until corrective actions are taken to insert the control rods or drop borated control material into the core to affect a full shutdown and to allow the reactor to be taken to a cold shutdown condition.

\subsection{Control Chemical Attack}

Chemical attack on fuel particles and on the graphite core structure can result from air or water ingress into the primary system. During normal operations and during some anticipated operational 
occurrences (AOOs) and accident sequences, contaminants are managed at the parts per million level by the HPS, which purifies a side stream from the primary system.

The likelihood of water entering the primary system is limited by the absence of high pressure and high energy sources of water in proximity to the primary system with the exception of the steam generator (SG). Under normal operating conditions, all other water coolers and heat exchangers operate at lower pressures than the pressure of the helium with which they exchange heat. Nevertheless, in the event of a tube leak in the higher pressure SG, the leak would be detected either by moisture monitors or by high primary coolant pressure. Either signal results in isolation of the SG to limit the amount of water ingress to the reactor. In addition the moisture monitor signal or reactor operator dumps the remaining SG inventory to water tanks to limit the primary system pressure rise, graphite-steam oxidation, and the moisture cleanup time. Core cooling can still be provided by the shutdown cooling system, and would limit the potential for chemical attack by lowering the graphite and fuel temperatures. If core cooling is not available, the potential of water or steam transport to the core would still be limited because the subcooled feedwater in the SG will not flash to steam unless the primary coolant helium pressure is below the water saturation pressure. If steam is generated and transported to the core, the reaction of steam and graphite is slow and endothermic and therefore is not self-sustaining. Exposure to moisture does not affect fuel particles, except for the very small fraction with defective coating layers. Moisture ingress does not cause additional particle failures in and of itself. Radionuclide release from defective particles would increase because of hydrolysis of fuel kernels, which temporarily increases radionuclide release, but overall radionuclide retention is adequately maintained to meet requirements [SWEC 1992].

The likelihood of a breach of the HPB, such that air ingress becomes a concern, is limited by the high quality associated with the pressure vessels and the limited size of penetrations. In the event of a breach, primary helium coolant would leak out until the inside and outside pressures equilibrate. Most notably, the high pressure helium would act to expel the reactor building air out the vent. Then, the ingress rate of the helium-air gas mixture would be small, as the gas mixture tries to enter the breach primarily by natural circulation and diffusion at the same time as helium coolant, which it is displacing, tries to exit through the same hole. Large gas mixture ingress rates would require an implausible scenario of breach of an ASME Code Section III vessel to set up an effective circulation path. However, even in that circumstance, the gas mixture flow would be restricted by the flow resistance characteristics in the core (e.g., high cooling channel length-to-diameter ratio, pebble bed flow resistance).

In contrast to coal and charcoal, graphite is a highly structured, highly dense, and very pure form of carbon. The properties of coal and charcoal that allow for self-sustained combustion include the following:

1. Impurities cause a high intrinsic rate of oxidation by catalyzing the reaction.

2. The high porosity provides a large surface area for oxidation and high diffusion rates of oxygen into the charcoal or coal, which results in more homogeneous oxidation rather than mass-transfer limited reactions that are confined to near the surface.

3. Charcoal and coal generate volatile gases (e.g., methane) that react exothermically, resulting in higher temperatures and higher oxidation rates.

4. Combustion of charcoal and coal results in the formation of a layer of porous ash, which allows oxygen to pass through but inhibits the heat loss by insulating the carbon and reducing the surface emissivity.

5. Charcoal and coal have lower thermal conductivities and smaller heat capacity than graphite, which results in higher temperatures and higher heat-up rates for a given amount of oxidation.

Man-made (artificial) graphites are engineered materials and exhibit none of the above properties. Nuclear-grade graphites have even lower levels of impurities than conventional graphites. As a result, 
they are even more difficult to oxidize. Demonstration tests have shown negligible mass loss for nucleargrade graphite under conditions for which charcoal and coal were completely consumed and reduced to ash. The combustion characteristics of graphite are more like that of diamond another highly structured and highly pure form of carbon.

Finally, the amount of air in the predominately helium mixture is limited by the exchange rate between the reactor building and the environment. As a result, the overall heat of reaction of air with graphite remains small relative to core decay heat. Also, any air in the gas mixture that enters the primary coolant will react with graphite elements and fuel matrix materials before it can reach and chemically react with the coated fuel particles.

In summary, control of chemical attack has been a focus of the safety approach from the inception of the HTGR. A combination of active and passive design features has been utilized with the inherent characteristics of the inert high-pressure helium, nuclear-grade graphite, and coated particle fuel to assure adequate safety margins. 


\section{RISK-INFORMED SAFETY APPROACH}

A risk-informed approach to supporting the licensing basis that, by definition, uses both probabilistic and deterministic elements has been introduced at an early stage in the NGNP design and licensing process. This approach differs from the current licensing framework, which was developed for reactors with a fundamentally different safety design philosophy. Risk insights to be developed from the NGNP Probabilistic Risk Assessment (PRA) are viewed as essential to developing a design that is optimized in meeting safety objectives and in interpreting the applicability of the existing requirements to the safety design approach of the NGNP HTGR. Results and insights from the PRA will be needed to assure the safety of the design against the NRC's Safety Goals [NRC 1986], and to determine whether any additional requirements or guidance may be necessary that are specific to the type of HTGR selected by the NGNP Project.

\subsection{Use of Probabilistic Risk Assessment}

The approach that will be followed to develop a PRA for the NGNP HTGR supports a specific set of PRA applications that include:

- Incorporation of risk insights from the PRA developed for the MHTGR in the late 1980s and early $1990 \mathrm{~s}$

- Evaluation of design alternatives and incorporation of risk insights into the design

- Input to the selection of LBEs

- Input to the safety classification of structures, systems, and components (SSCs)

- Risk-informed evaluation of defense-in-depth

The technical approach to performing the NGNP HTGR PRA is described in the NGNP PRA white paper $^{\mathrm{a}}$. Due to the inherent and passive features of the NGNP HTGR, the approach to modeling initiating events and event sequences will be modified in terms of size and complexity in comparison to that in an LWR PRA model. These adjustments will not diminish the quality of the PRA, but will facilitate the capability to model more accurately the HTGR features, events, and plant response.

The NGNP HTGR PRA model will be structured somewhat differently than the traditional Level 1-23 model for an LWR PRA as defined in NUREG/CR-2300 [NRC 1983], for several reasons. There is nothing comparable to a Level 1 PRA for the NGNP HTGR, because there is no plant state comparable to 'core damage' as defined for an LWR. The available definitions of 'core damage' are specific to LWRs, are not applicable to HTGRs such as the NGNP HTGR, and hence there is no CDF risk metric. Such core damage states are precluded by the NGNP HTGR safety design approach as will be verified by calculations in the COL Application. Similarly, the NGNP HTGR PRA model does not use "large early release frequency" as a risk metric as defined for an LWR. While the NGNP HTGR PRA does not calculate CDF or LERF metrics, it does calculate several NGNP HTGR-specific plant end-state frequencies that correspond with the LBEs. The methodology for identifying the NGNP HTGR-specific end states will be discussed in detail in the forthcoming NGNP white paper on PRA ${ }^{\mathrm{a}}$.

A simplification in the NGNP HTGR PRA model structure stems from the relative simplicity of the NGNP HTGR in terms of the number of SSCs and events that need to be modeled. This factor lends itself to the capability to define a continuous event sequence development spanning from initiating events to release categories for which mechanistic source terms and radiological consequences can be calculated. For organizing the computer model, this continuous event sequence model may be broken up into different stages of event trees to represent the different responses of the plant systems and structures, and

\footnotetext{
a INL, 2011, "Next Generation Nuclear Plant Probabilistic Risk Assessment White Paper," Idaho National Laboratory, INL/EXT11-21270, DRAFT.
} 
in this respect, the NGNP HTGR PRA model may exhibit some similarities with the classic Level 1-2-3 LWR PRA structure. However, in the end, the elements of the NGNP HTGR PRA are combined into a single, event sequence model framework that starts with initiating events occurring in different plant operating states, and ends in NGNP HTGR-specific event families and release categories, including appropriate categories for successful prevention of release. A given release category will contain one or more event families for which frequencies, mechanistic source terms and offsite consequences are calculated. The integral NGNP HTGR PRA encompasses the functions of a full-scope Level 1-2-3 LWR PRA.

The modular aspect of the HTGR creates the potential for multiple reactor modules to be located at the same site with some systems shared between the modules. The PRA will account for the risk of multiple modules. The existence of multiple modules increases the site-wide likelihood of scenarios that impact a single module independently, and it creates the potential for scenarios that involve multiple modules as well as the potential for a mechanistic source term involving two or more reactors. These modular reactor considerations will impact the scope and level of detail of the PRA.

\subsection{Licensing Basis Event Selection}

LBEs are a comprehensive set of event sequences used in development of the license application that form the basis for plant analysis and that represent the plant's characteristic performance in all analyzed frequency and consequence ranges. LBEs include conditions of normal operation, including AOOs, design basis events (DBEs), and beyond design basis events (BDBEs) that inform the deterministically selected DBAs. AOOs, DBEs, and BDBEs include the plant response of both safety-related and nonsafety-related SSCs. In contrast, DBAs include the plant response of only safety-related SSCs. The LBE Selection white paper describes a systematic performance-based and risk-informed methodology for selecting and classifying LBEs for the NGNP design, consistent with current NRC policies and guidance on the application of deterministic design criteria and the use of PRA techniques [INL 2010c]. The methodology integrates the use of deterministic safety principles and PRA insights as critical inputs into the selection of LBEs. These events include specific scenarios to which mechanistic source terms are derived and assessed against offsite dose criteria.

LBE selection is an integral part of the overall design process. The design attributes of the plant influence the type and sequence of events, but the identified LBEs can, in turn, affect the final design. Once an initial set of LBEs is identified, the design can be refined to reduce the frequency and/or consequence of a given LBE. The following process is used for each phase of the detailed design development:

1. A deterministic approach is used to select an initial event set providing a starting point for a given phase of the design process. For example, a set of initial events developed from conceptual design provides the starting point for preliminary design.

2. The LBEs are updated as the design and analysis progress. The PRA is developed and revised as the design matures. This begins to risk-inform the LBE event sequences with insights gained from the design phase PRA.

3. A review of the LBEs is performed at the end of each design phase to evaluate conservatisms in the selected events.

The PRA will be used to evaluate the safety characteristics of the design and to provide a structured framework from which the initial set of LBEs will be risk-informed. In addition, engineering judgment and utilization of HTGR experience will continue to be used to ensure that LBE selection and classification is complete. The rationale for use of risk-assessment techniques is as follows: 
- Using a PRA to aid in the development of events that are included in the licensing basis supports the establishment of a comprehensive safety basis. By its nature, PRA development is a rigorous process that considers the comprehensive performance of the facility design.

- Probabilistic methods for event selection, SSC safety classification, special treatment identification, and integration of defense-in-depth strategies will optimize the safety characteristics of the HTGR design.

- The PRA provides a rational approach for identifying, understanding, and addressing uncertainties.

The PRA will systematically enumerate event sequences and assesses the frequency and consequence of each event sequence. Event initiators will include internal, common cause, and external events and all plant modes of operation, i.e., full power, partial power, shutdown, and refueling.

\subsection{Structures, Systems, and Components Safety Classification}

The NGNP risk-informed and performance-based licensing approach includes three categories of safety classification for SSCs. Details on the safety classification process are described in the SSC Safety Classification white paper [INL 2010d]. The three categories are:

Safety-Related SSCs:

- This category is for SSCs relied on to perform the required safety functions to mitigate the public consequences of DBAs and DBEs to comply with the TLRC.

- This category is also for SSCs relied on to perform required safety functions to prevent the frequency of BDBEs with consequences greater than the 10 CFR $\$ 50.34$ dose limits from increasing in frequency into the DBE region.

Non-Safety-Related with Special Treatment:

- This category is for SSCs relied on to perform safety functions to mitigate the consequences of AOOs to comply with the TLRC.

- This category is also for SSCs relied on to perform safety functions to prevent the frequency of DBEs with consequences greater than the 10 CFR Part 20 offsite dose limits from increasing in frequency into the $\mathrm{AOO}$ region.

Non-Safety-Related with No Special Treatment

- This category is for risk-significant SSCs not included in either of the above two categories.

The three categories of safety classes defined above are defined in the context of how the frequencies and doses of the LBEs are controlled by the capabilities and reliabilities of the SSCs in relation to the TLRC. SSCs may participate in one or more kinds of LBEs as described in the SSC Safety Classification white paper [INL 2010d].

\subsection{Defense-In-Depth}

The principles of defense-in-depth are applied in the design, construction, and operation of existing and advanced nuclear power plants; the NGNP design is no exception. In the design and analysis process for the NGNP HTGR, the "historic" deterministic approach is integrated with a risk-informed performance-based evaluation methodology to ensure that selected design features provide the required level of safety and defense-in-depth. The result is a set of conservative design features combined with inherent reactor characteristics, passive design features, and active systems to (1) prevent transients and accidents, (2) ensure the performance of safety functions, (3) prevent the release of radioactive material, and (4) mitigate the consequences of accidents. The principles of multiple, independent, and concentric barriers to radionuclide transport and release are assessed for each significant source of radioactive material to assure that defense-in-depth has been maintained. In addition, the principles of design margin, 
redundancy, and diversity are applied in the design of the SSCs that support the required safety functions and serve to support and maintain the integrity and effectiveness of these barriers. The defense-in-depth strategies ensure that TLRC are met, adequate safety margins are achieved, deterministic principles of defense-in-depth are applied, and uncertainties in the reliabilities and capabilities of the SSCs providing the required safety functions are adequately addressed over the life of the plant [INL 2009].

The proposed risk-informed and performance-based framework for defense-in-depth recognizes the following major elements as shown in Figure 10.

- Plant Capability Defense-in-Depth reflects the decisions made by the designer in the selection of functions, and SSCs for the design that assure defense-in-depth in the physical plant.

- Programmatic Defense-in-Depth reflects the decisions made regarding the processes of manufacturing, constructing, operating, maintaining, testing, and inspecting the plant and the processes undertaken that ensure plant safety throughout the lifetime of the plant.

- Risk-Informed Evaluation of defense-in-depth reflects the development and evaluation of strategies that manage the risks of accidents, including the strategies of accident prevention and mitigation. This aspect of defense-in-depth also provides the framework for performing deterministic and probabilistic safety evaluations that help determine how well various Plant Capability Defense-in-Depth and Programmatic Defense-in-Depth strategies have been implemented. The goal of this evaluation is to demonstrate the adequacy and sufficiency of all physical and programmatic measures to assure that defense-in-depth is maintained in the design.

A more detailed definition of the elements of the approach to defense-in-depth and its risk-informed and performance-based steps is provided in the NGNP white paper on that subject [INL 2009].

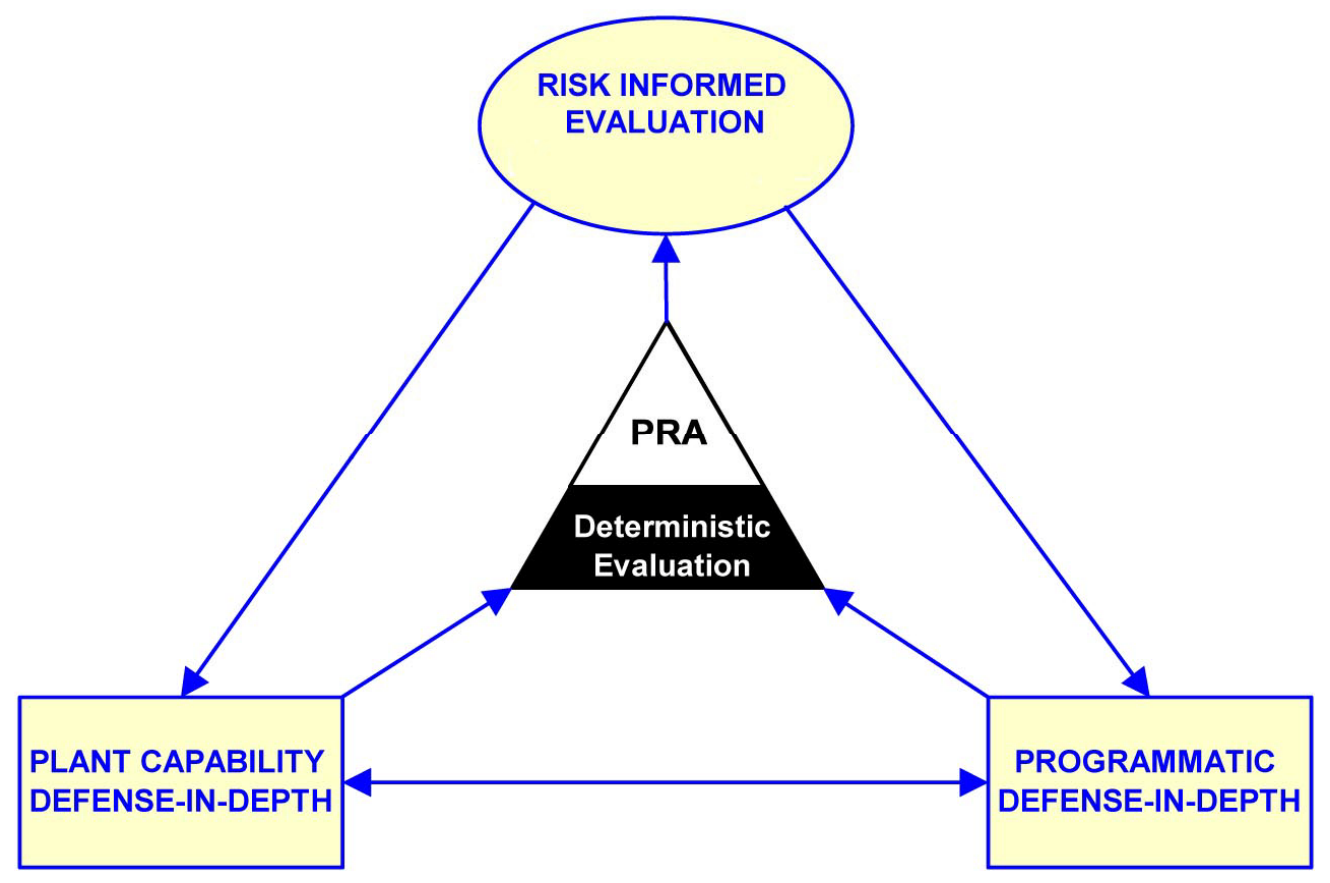

Figure 10. Elements of the NGNP defense-in-depth framework. 


\section{SUMMARY}

The discussion in this information paper is expected to provide the NRC staff and public stakeholders with a fundamental understanding of the HTGR concept and how the safety approach meets public safety requirements. The information provided is summarized below.

Modular HTGR technology was selected for the NGNP project because it can provide both electricity and high temperature process heat needed for industrial processes. HTGR technology is expected to supply process heat as an alternative to existing carbon-based energy sources, thereby significantly reducing the use of fossil fuels and their greenhouse gas releases.

HTGRs have a long history beginning in the early 60's with the Dragon Project, Peach Bottom Unit 1 , and the AVR prototype test reactor. These early reactors were used extensively for testing and verification of HTGR technology particularly a variety of HTGR fuels. The early success of these reactors led to larger demonstration plants in the U.S. (FSV) and Germany (THTR).

Modular HTGR development began in Germany and the U.S. in the 1980s. The objective was to design a reactor system in such a way that the decay heat could be removed passively under all circumstances. To maintain the coated-particle fuel temperatures below damage limits during passive decay heat removal, the core's physical size and shape and power density were optimized. This modularization work forms the basis for the current generation of HTGRs.

The primary safety objective of the NGNP Project is to limit dose from accidental releases so that regulatory requirements are met at an $\mathrm{EAB}$ coinciding with the site boundary. To achieve this safety objective, the HTGR relies on the inherent safety characteristics of TRISO-coated fuel particles, graphite moderator, and helium coolant, along with the passive heat removal capability of a low-power density core within an uninsulated steel reactor vessel.

The five barriers to radionuclide release that form a functional containment system for modular HTGRs are: the fuel particle kernel, the fuel particle coatings, the core graphite and carbonaceous fuel matrix material, the helium pressure boundary, and the reactor building. The most important of these barriers, particularly during accidents, is the silicon carbide and pyrocarbon coatings of each fuel particle.

The safety design approach for the HTGR controls radionuclides primarily at their source with the coated fuel particle. The required safety functions that protect the integrity of the fuel are: remove core heat, control heat generation, and control chemical attack. Successfully performing these functions will keep the consequences of the DBEs and DBAs within the TLRC offsite dose limits of 10 CFR 50.34. These functions must address challenges such as leaks and breaks in the helium pressure boundary, loss of forced cooling, air ingress, water ingress, and reactivity-initiated accidents.

A risk-informed approach supports both the NGNP design and licensing process. Risk insights from an NGNP PRA support the following: evaluation of design alternatives and incorporation of risk insights into the design, input to the selection of LBEs, input to the safety classification of SSCs, and riskinformed evaluation of defense-in-depth. LBEs include AOOs, DBEs, BDBEs; they also include deterministically selected DBAs, which only take credit for the plant response of safety-related SSCs. Safety classification divides SSCs into three categories: safety-related, non-safety-related with special treatment, and non-safety-related with no special treatment. The NGNP defense-in-depth framework has three elements: plant capability defense-in-depth, programmatic defense-in-depth, and risk-informed evaluation of defense-in-depth. Deterministic and probabilistic safety evaluations determine how well the defense-in-depth strategies have been implemented. The goal of these evaluations is to demonstrate the adequacy and sufficiency of all physical and programmatic measure to assure that defense-in-depth is maintained in the design and operation of the modular HTGR. 


\section{REFERENCES}

ANS, 1984, Melese, Gilbert, and Robert Katz, "Thermal and Flow Design of Helium-Cooled Reactors," American Nuclear Society, La Grange Park, IL, 1984.

DOE, 1992,"Preliminary Safety Information Document for the Standard MHTGR,” Department of Energy, HTGR-86-024, Amendment 13, September 1992.

DOE/NRC, 2008, "Next Generation Nuclear Plant Licensing Strategy - A Report to Congress," Dept. of Energy / Nuclear Regulatory Commission, August 2008.

EPA, 1992, "Manual of Protective Action Guides and Protective Actions for Nuclear Incidents," U.S. Environmental Protection Agency, EPA 400-R-92-001, May 1992.

EPAct, 2005, Public Law 109-58, "Energy Policy Act of 2005," $109^{\text {th }}$ Congress, August 8, 2005.

GA, 1976, Scheffel, W. J., N. L. Baldwin, and R. W. Tomlin, "Operating History Report for the Peach Bottom HTGR, Volume 1: Reactor Operating History," General Atomic, GA-A13907, Vol. 1, August 1976.

GA, 1988, "Probabilistic Risk Assessment for the Standard Modular High Temperature Gas-Cooled Reactor," General Atomics, DOE-HTGR-86011, Rev. 5, April 1988.

GA, 2010, “Conceptual Design Report - Steam Cycle Modular Helium Reactor (SC-MHR) Demonstration Plant," General Atomics, NGNP-R00016, Rev. 0, December 2010.

Hanson, 2004, Hanson, D. L., "A Review of Radionuclide Release from HTGR Cores during Normal Operation,” Electric Power Research Institute, Report 1009382, February 2004.

Hoinkis, 1983, Hoinkis, E., "Transport of Fission Products in Matrix and Graphite," Proceedings of a Colloquium held at the Hahn Meitner Institut in Berlin from 9 to 11 November, 1981, HMI B372, June 1983.

HTR, 2010, Shinohara, M., et al., "Long-Term High-Temperature Operation in the HTTR: (1) Outline and Main Test Results," Paper 167, Proceedings of HTR 2010, Prague, Czech Republic, October 18$20,2010$.

IAEA, 1997, "Fuel Performance and Fission Product Behavior in Gas Cooled Reactors," International Atomic Energy Agency, TECDOC-978, November 1997.

INL 2009, "Next Generation Nuclear Plant Defense-in-Depth Approach,” Idaho National Laboratory, INL/EXT-09-17319, December 2009.

INL, 2010a, "NGNP Fuel Qualification White Paper," Idaho National Laboratory, INL/EXT-10-17686, July 2010.

INL, 2010b, "Mechanistic Source Terms White Paper," Idaho National Laboratory, INL/EXT-10-17997, Rev. 0, July 2010.

INL, 2010c, "Licensing Basis Event Selection White Paper," Idaho National Laboratory, INL/EXT-1019521, September 2010.

INL, 2010d, "Next Generation Nuclear Plant Structures, Systems, and Components Safety Classification White Paper," Idaho National Laboratory, INL/EXT-19509, September 2010.

INL, 2010e, "Summary for the Next Generation Nuclear Plant Project in Review," Idaho National Laboratory, INL/EXT-10-19142, Rev. 1, September 2010.

Martin, R. C., 1993, "Compilation of Fuel Performance and Fission Product Transport Models and Database for MHTGR Design,” Oak Ridge National Laboratory, ORNL/NPR-91/6, October 1993. 
NED, 1984, Reutler, H., and G. H. Lohnert, “Advantages of Going Modular in HTRs," Nuclear Engineering and Design 78 (1984), 129-136.

NED, 1990a, Gottaut, H., and K. Krüger, "Results of Experiments at the AVR Reactor," Nuclear Engineering and Design 121 (1990), 143-153.

NED, 1990b, Bäumer, R., et al., "Construction and Operating Experience with the 300-MW THTR Nuclear Power Plant,” Nuclear Engineering and Design 121 (1990), 155-166.

NED, 2009, Zhang, Z. et al., "Current Status and Technical Description of Chinese 2x250 MW th HTRPM Demonstration Plant," Nuclear Engineering and Design 239 (2009), 1212-1219.

NRC, 1983, U.S. Nuclear Regulatory Commission, "PRA Procedures Guide,” NUREG/CR-2300, January 1983.

NRC, 1986, U.S. Nuclear Regulatory Commission, "Safety Goals for the Operations of Nuclear Power Plants; Policy Statement," Federal Register, Vol. 51, No. 149, pp. 28044-28049, August 4, 1986 (republished with corrections, Vol. 51, No. 160, pp. 30028-30033, August 21, 1986).

NRC, 2008, U.S. Nuclear Regulatory Commission, "Updated Policy Statement on Regulation of Advanced Reactors," SECY-08-130, September 11, 2008 and Staff Requirements Memorandum March 26, 2008.

NW, 1989, "PSC Shuts Fort St. Vrain for Good After Tube Cracks Found," Nucleonics Week 30 (35) :3, McGraw-Hill, August 31, 1989.

OECD, 1978, "A Summary \& Evaluation of the Achievements of the Dragon Project and Its Contribution to the Development of the High Temperature Reactor," OECD Dragon Project, DPR-1000, November 1978 .

SWEC, 1992, "Preliminary Safety Information Document for the Standard MHTGR," Stone \& Webster Engineering Corp., HTGR-86024, Rev. 13, September 1992. 


\section{Appendix A}

\section{History of the International Development of High Temperature Gas-Cooled Reactors (HTGRs) from the 1950 s to the 1980 s}




\section{Appendix A History of the International Development of High Temperature Gas- Cooled Reactors (HTGRs) from the 1950s to the 1980s}

High-Temperature Gas-Cooled Reactors (HTGRs) are part of a larger family of gas-cooled reactors. Air-cooled graphite reactors were first built either for experimental purposes or to produce plutonium. The earliest commercial gas-cooled power reactors used carbon dioxide $\left(\mathrm{CO}_{2}\right)$ as their coolant and were primarily developed and used in the United Kingdom (UK) and France. To produce higher outlet temperatures, helium was chosen as the coolant and an all ceramic core was developed for HTGRs. Early HTGRs were small test reactors and prototypes used primarily for fuel and technology development as noted below.

The first HTGR was built at the UK Atomic Energy Authority Establishment in Winfrith, Dorset, UK by the Organization for Economic Cooperation and Development (OECD) High Temperature Reactor Project (commonly referred to as the Dragon Project) [OECD 1978]. The Dragon Reactor was a 20 $\mathrm{MW}(\mathrm{t})$ test reactor. It operated at $2 \mathrm{MPa}$ primary system pressure, with a core inlet temperature of $350{ }^{\circ} \mathrm{C}$ and an outlet temperature of $750{ }^{\circ} \mathrm{C}$. The reactor went critical on August 23, 1964 and operated successfully until permanent reactor shutdown near the end of 1975. The core consisted of 37 hexagonal fuel-moderator assemblies with each assembly composed of seven graphite clad fuel rods. The initial core consisted of uranium and thorium carbide. Test elements of oxides and carbides were also tested, including multi-hole graphite fuel blocks for testing various fuel pins. The coated particle fuel used was mostly the tri-structural isotropic (TRISO) fuel design in which a SiC layer is sandwiched between two pyrocarbon (PyC) layers. Satisfactory experience was obtained with a variety of coated fissile and/or fertile particles at burnups, fast neutron doses, and temperatures required for power reactors [ANS 1984].

Research and development (R\&D) for the Dragon Project in the UK was closely followed by similar R\&D in the United States (U.S.) leading to the construction and operation of Peach Bottom Unit 1 [GA 1976]. The Peach Bottom HTGR was a $115 \mathrm{MW}(\mathrm{t}), 40 \mathrm{MW}(\mathrm{e})$ demonstration plant. It operated at 2.4 MPa primary system pressure with a core inlet temperature of $350{ }^{\circ} \mathrm{C}$ and an outlet temperature of 750 ${ }^{\circ} \mathrm{C}$. The reactor went critical on March 3, 1966 and operated successfully until permanent reactor shutdown near the end of 1974 . The goal of this prototype plant was to demonstrate production of $538{ }^{\circ} \mathrm{C}$ steam from a reactor with good neutron economy and high fuel burnup. The $35 \%$ net thermal efficiency of Peach Bottom 1 remained the highest efficiency of any nuclear power plant in the world until its scheduled shutdown in 1974. It was eventually surpassed when the Phoenix liquid-metal fast breeder reactor was operated in France at 40\% efficiency.

The Peach Bottom core consisted of 804 graphite clad fuel elements, which were $8.9 \mathrm{~cm}$ (3.5 in.) in diameter and $3.66 \mathrm{~m}$ (12 ft long). The first core contained fuel compacts in which the fuel particles were coated with a single layer of PyC. Radial expansion due to fuel swelling resulted in cracked sleeves in 90 elements. This first core was replaced by a core containing bi-structural isotropic (BISO) fuel particles coated with a double layer of $\mathrm{PyC}$; a low density inner layer, and a high density outer layer. No cracked elements occurred with the second core. The Peach Bottom reactor was used extensively for irradiation of fuel elements for HTGRs. A total of 33 test elements containing more than 1500 test fuel rods were successfully irradiated [ANS 1984].

The AVR was the first prototype pebble bed reactor. It was constructed at the Jülich Nuclear Research Center in the Federal Republic of Germany (FRG). The pebble bed was made up of 100,000 six-cm in diameter spheres. Each sphere has an inner region of graphite matrix material and coated fuel particles and a fuel-free graphite shell. The AVR was a $46 \mathrm{MW}(\mathrm{t}), 15 \mathrm{MW}(\mathrm{e})$ test reactor. It operated at 1.1 MPa primary system pressure with a core inlet temperature of $270{ }^{\circ} \mathrm{C}$ and an outlet temperature of up to $950{ }^{\circ} \mathrm{C}$. The AVR went critical in August 1966 and reached full power operation in February 1968. The AVR was first operated at a core outlet temperature of $750{ }^{\circ} \mathrm{C}$ and later increased to the design value 
of $850^{\circ} \mathrm{C}$ in 1972 . In early 1974 , the core outlet temperature was increased to $950{ }^{\circ} \mathrm{C}$, with an inlet temperature of $270^{\circ} \mathrm{C}$. Shutdown of the reactor occurred at the end of 1988 [ANS 1984].

The primary goal of AVR was to demonstrate the feasibility and safe operation of the pebble bed reactor concept and to gather operating experience. As the program progressed, a number of experiments were performed to gather additional data. The experiments included a loss of flow test in which the shutdown rods were not inserted. The reactor quickly shut itself down due to negative temperature coefficient. Eventually after xenon decayed away a day later, the reactor became recritical and stabilized at a low power of $300 \mathrm{~kW}(\sim 1 \%)$. Another experiment was performed to simulate a loss of coolant accident and demonstrate safe residual heat removal without active cooling measures. Comparisons between experimental measurements and analytical predictions were used to validate computer programs [NED 1990a].

The AVR was also used as a test bed for testing pebble fuel elements. A total of 14 different fuel element types were tested under operating conditions involving large numbers of pebbles. Initially the pebble fuel used BISO coated uranium/thorium carbide fuel particles. Beginning in 1971, new pebble fuel for AVR used oxide fuel kernels. After 1982, the fuel particles for new pebbles used TRISO coated uranium oxide fuel particles. Prior to 1982, all of the fuel used high enriched uranium. The addition of low enriched uranium (LEU) fuel in 1982 resulted in an increase in silver radionuclide activity in the primary circuit which is characteristic of LEU-fueled HTGRs where a portion of the fissions occurs in bred plutonium. Elevated levels of silver activity in the primary circuit contributed to occupational doses [NED 1990a].

As part of the U.S. Atomic Energy Commission Power Reactor Demonstration Program, General Atomic constructed the FSV HTGR for the Public Service Company of Colorado. The FSV reactor was designed to operate at a core power level of $842 \mathrm{MW}(\mathrm{t})$ with a net electric output of $330 \mathrm{MW}(\mathrm{e})$. FSV was the first HTGR to use stacked columns of prismatic fuel elements, i.e., hexagonal fuel elements approximately 31 inches high and 14 inches across the flats. The TRISO coated fuel particles included $(\mathrm{Th}, \mathrm{U})$ carbide fissile particles and Th carbide fertile particles. The reactor operated at a pressure of 4.8 $\mathrm{MPa}$ with a core inlet temperature of $405^{\circ} \mathrm{C}$ and an outlet temperature of $775^{\circ} \mathrm{C}$. Unlike previous HTGRs, FSV used a prestressed concrete reactor vessel (PCRV) instead of a steel pressure vessel. The FSV reactor went critical in January 1974. Accidental insertion of water into the reactor cavity of the PCRV, overheating of the PCRV liner, rerouting of essential electrical cables, and modifications to the fire protection system caused delays in the rise-to-power testing. By the end of 1976, testing had reached $28 \%$ power at which point the first electricity was generated. Core region outlet temperature fluctuations in late 1977 resulted in a power limitation of $70 \%$ until restraint devices were installed on the top of the core to prevent movement of the fuel columns. Testing above $70 \%$ power was performed in the spring of 1981 and 100\% power was reached in November 1981 [ANS 1984].

Moisture ingress from the water bearing system on the circulators and its associated long-term corrosive effect on primary system components was the most important issue for FSV availability and safety. Moisture ingress had impacted both the control rod drives and reserve shutdown systems to the point where six control rod pairs failed to scram the reactor during a June 23, 1984 event. On August 18, 1989, the plant was shut down to repair a stuck control rod pair; however, during the shutdown, numerous cracks were discovered in several steam generator main steam ring headers. The required repairs were determined to be too expensive to justify continued operation, so the FSV reactor was permanently shutdown in August 1989 [NW 1989].

Based on the early success of the AVR and the pebble bed reactor concept, a German utility undertook the construction of a $300 \mathrm{MW}$ (e) pebble bed HTGR demonstration plant in Schmehausen, West Germany. The Thorium High-Temperature Reactor (THTR) operated at a pressure of 3.9 MPa with a core inlet temperature of $250{ }^{\circ} \mathrm{C}$ and an outlet temperature of $750{ }^{\circ} \mathrm{C}$. Unlike AVR in which the reactor was in an uninsulated steel pressure vessel, the entire primary system was contained in a PCRV similar to 
the FSV reactor in the U.S.. THTR went critical in September 1983 and started full power operation in September 1986. Due to financial risks associated with fuel element supply problems, fuel element disposal problems, and problems regarding the permanent operating license, (all issues associated with the political climate in the German state of North Rhine-Westphalia) THTR was shutdown in September 1988 after 423 full power days of operation. In spite of the short operating time, the experience gained from the commissioning and operation has furnished an essential contribution to the research objectives set for the THTR [NED 1990b].

In the 1970s, HTGR designers at General Atomics developed designs for large, prismatic block reactors based upon the technologies used in the Fort St. Vrain Nuclear Generating Station. The power levels of these designs ranged from 2000 to $4000 \mathrm{MW}(\mathrm{t})$. Construction permit applications for these designs were submitted to the NRC by utility customers, and regulatory review, including construction permit safety evaluation reports and an ACRS letter, were underway prior to cancellation of the projects in the late 1970 s. 